\title{
The Effect of an Increase of the Retirement Age on the Health, Well-Being, and Labor Force Participation of Older Workers: a Systematic Literature Review
}

\author{
Patrick Pilipiec $^{1} \cdot$ Wim Groot ${ }^{2} \cdot$ Milena Pavlova $^{3}$
}

Received: 23 August 2019 / Accepted: 21 April 2020/ Published online: 6 May 2020

(C) The Author(s) 2020

\begin{abstract}
To sustain a viable public pension system, many governments have increased the statutory retirement age and delayed the age of entitlement to public pension benefits. This systematic literature review investigates the empirical evidence on the effects of increasing the retirement age on the health, well-being, and labor force participation of older workers. Optimized and broad search queries were used to search for empirical evidence in four databases: EconLit, PsycINFO, PubMed, and SocINDEX. The systematic literature search was conducted in May 2019. Snowballing was performed on the reference lists of the publications to find additional studies. The quality of the included studies was also examined. The PRISMA guidelines were used to guide this systematic literature review. Nineteen studies were included in this review. Twelve studies estimated the effect of an increase in the statutory retirement age, and seven studies examined working beyond the retirement age. The reported findings were classified into health-related outcomes, well-being, and the effects on labor force participation and the perception of the retirement age. The reported findings regarding health-related outcomes and well-being were not comparable. The increase of the retirement age has increased labor force participation among older workers and has increased the preferred and expected retirement age in the direction of the public pension reform. However, evidence on the effects of an increase of the retirement age on the health and well-being of older workers remains scarce and inconclusive.
\end{abstract}

Keywords Health · Job satisfaction - Labor force participation · Public pension reform · Statutory retirement age $\cdot$ Well-being

Patrick Pilipiec

patrick.pilipiec@maastrichtuniversity.nl

Extended author information available on the last page of the article 


\section{Introduction}

One of the most important challenges that all countries are confronted with, is that their demographic structure is changing significantly (Vogel et al. 2017). Although differences between individual countries exist, the overall world population is rapidly growing older (OECD 2006). As life expectancy is increasing and birth rates over the past decades have declined, the age composition of the population has changed. Consequently, population aging challenges countries both socially and economically (OECD 2006).

Population aging has a negative effect on the sustainability of public pension systems. Many modern societies have a public pay-as-you-go (PAYG) pension system, where present workers provide financial contributions to current pension recipients (Domonkos 2015). However, the co-occurrence of a long-term decrease in fertility and an increase in the share of pension recipients who also increasingly live to an older age, results in shrinking financial contributions and increasing costs, which jeopardizes the solvency of these public pension systems (Bernal and Vermeulen 2014; European Commission 2006; Harper 2015; Hess 2017; Lüthen 2016; Walker 2008). The oldage dependency ratio is frequently used to measure the sustainability of pension systems and social policies (Domonkos 2015). For example, Eurostat reported that for just 20 years, the old-age dependency ratio in Europe has increased from approximately 22\% in 1997, to almost 30\% in 2017 (Eurostat 2018). This means that, while five persons of working age supported one person at the age of 65 or older in 1997 , only three working persons supported one older person in 2017. This illustrates the major challenge regarding the pension systems that countries are confronted with.

Wheaton and Crimmins (2012) report that older age groups have a large potential for labor force participation because they often have sufficient physical ability to work. The negative financial burden on the sustainability of public pension programs in many countries is amplified by an already low and decreasing labor market participation by these older workers (Staubli and Zweimüller 2013). Thus, employing more older workers beyond the traditional retirement age may decrease the financial burden to sustain public pension programs.

Although the literature often uses retirement age and pension age interchangeably, there is an important distinction between both concepts. The retirement age refers to the legal age for obligatory and permanent withdrawal from the labor market (Banks and Smith 2006; Denton and Spencer 2009; Wang and Shi 2014). The pension age refers to a legal age for eligibility to pension benefits. In countries where the retirement and pension age are connected, once a person reaches the retirement age, he is expected to retire from the labor market and becomes eligible for pension benefits that serve as a replacement for income from paid work. However, in many countries, there is no legal retirement age or older workers can decide to continue working after they become eligible for pension benefits, while people with wealth may decide to retire from the labor market before they become eligible for pension benefits.

To address the demographic challenges and to sustain a financially sound public PAYG pension system in long-term, various authors suggest that the statutory retirement age needs to be increased (Barr 2012; Buyse et al. 2013; De Wind et al. 2016; Engels et al. 2017; European Commission 2012, 2013; Kohli and Arza 2011; Komp 2018; OECD 
2006; Tolos et al. 2014). In addition to delaying the age for eligibility to pension benefits, such policy reform also increases the available workforce by employing more older workers who can financially contribute to the social security system (Atalay and Barrett 2014; Buyse et al. 2013; Hernæs et al. 2016; Komp 2018). Furthermore, increased labor force participation also increases labor tax revenues (Wheaton and Crimmins 2012).

Consequently, in the past two decades, many countries have initiated public pension reforms to increase the statutory retirement age (Bernal and Vermeulen 2014; Bozio, 2008; Lüthen 2016; Reynolds et al. 2012; Sewdas et al. 2017; Whitehouse et al. 2009), while some other governments are planning such reforms (Wahrendorf et al. 2017). Although pension reforms differ between countries, one common element is that they limit early retirement schemes and increase the age for entitlement to pension benefits (OECD 2019). For example, in 2018, the pension age for males was 51 years in Turkey, while all genders could retire at the age of 67 in Iceland, Italy, and Norway (OECD 2019). If current pension reforms are fully implemented, the retirement age in the future will be between 62 years (in Greece, Luxembourg, Slovenia, and Turkey) and 71 years (in Denmark, Estonia, Italy, and the Netherlands) (OECD 2019). The age for eligibility to pension benefits could however even be after age 71 (OECD 2019). Studies report that the public pension reforms have indeed increased the actual retirement age (Engels et al. 2017; Hess 2017; Hofäcker et al. 2015; Komp 2018) and that the differences in the actual retirement age between and within countries were reduced (Komp 2018).

Therefore, as older workers are now obliged to prolong their participation in the labor market, it is relevant to identify the effects of the policy reforms to increase the statutory retirement age, on the cognitive and physical functioning of older workers (cf. Stenholm and Vahtera, 2017). Moreover, facilitating and engaging older workers to work healthily and productively to an older age is becoming more important (De Wind et al. 2016; Templer et al. 2010). Therefore, it is relevant to examine the effect of an increase of the retirement age on the labor force participation of older workers.

Naturally, older workers may experience difficulties to adjust to the idea that they have to work longer, may experience that their human capital is deprecating, or that they need additional support to upgrade their knowledge and skills (OECD 2006). Likewise, older workers are more likely to have disabilities and other health problems (De Meijer et al. 2013). In addition, well-being becomes more relevant as workers become older. For example, job satisfaction was found to be an important determinant for retirement decisions (Kosloski et al. 2001). It is therefore important to investigate whether pension reforms that aim to increase the labor force participation, unintendedly decrease job satisfaction, because lower job satisfaction could consequently result in attrition of older workers from the labor market (Sewdas et al. 2017).

Furthermore, investigating the effect of an increase of the retirement age on older workers has great societal relevance. For example, the increase of the statutory retirement age resulted in public protests in France (CBS News 2010; Reguly 2012), Russia (BBC News 2018; Heintz 2018), Spain (Reguly 2012), and the United Kingdom (Heintz 2018; Hill 2018). In addition, in the Netherlands, the pension 
reform that increased the statutory retirement age remains a highly debated topic, where strong public resistance exists against this policy reform (Boschman and Van Alphen 2018; Henkens et al. 2016; MAX Vandaag 2016; PlusOnline 2016).

However, to the best of our knowledge, no systematic literature review of the available evidence has been performed on the effects of an increase of the retirement age on the health, well-being, and labor force participation of older workers. Although health becomes an increasingly important determinant for labor force participation among older workers, limited research has been done on the effects of delayed retirement on health (Atalay and Barrett 2014). Studying the effects of later retirement is particularly relevant given the assumed effectiveness of this policy reform and the fact that many countries are in the process of increasing the retirement age. Instead, much research has focused on the determinants of the decision to retire earlier than required, or on the overall effect of retirement on health-related outcomes (Nishimura, Nishimura et al. 2018). Therefore, this systematic literature review analyses the evidence on the effects of an increase of the retirement age on the health, well-being, and labor force participation of older workers.

\section{Methods}

The Preferred Reporting Items for Systematic Reviews and Meta-Analyses (PRISMA) guidelines were used to guide this systematic literature review (Liberati et al. 2009; Moher et al. 2009). The systematic literature search was conducted in May 2019.

\section{Information Sources}

Four databases were selected to ascertain that the disciplines involved (physical health and medical studies, economics, public policy, and mental health and wellbeing) were covered. These databases are PubMed, EconLit, SocINDEX, and PsycINFO, respectively. Studies were only included if written in English and published starting from the year 2000.

\section{Search Strategy}

In collaboration with two database specialists from the Maastricht University Library, an optimized search strategy for each of the four databases was formulated (see Appendix 1). The search strategy comprised of four search blocks: Employees, a public pension reform or increased retirement age, causality or associations, and outcomes for employees on the micro-level. For each block, a query was constructed that included relevant concepts and synonyms using the OR-operator; these four blocks were then combined with the AND-operator. Subsequently, filters were applied for publication type, publication date, language, and search results were, if supported, limited to peer-reviewed journals.

Each database was then searched using the optimized search strategy and databasespecific filters (see Appendix 1). Subsequently, the deduplication method by Bramer and colleagues was used to remove duplicate results (Bramer et al. 2016). 


\section{Study Selection}

Eligible studies were selected in three phases. First, the titles were screened for the occurrence of terms that indicated public pension, retirement age, and causality or associations. Only relevant publications were retained. Second, the abstracts of the remaining studies were screened for studies that investigated either the effects of a public pension reform that increased the statutory retirement age, or prolonged work participation beyond the retirement age for older workers. Irrelevant studies were omitted. Third, the full text of each publication was read to ascertain that the studies indeed investigated either the effects of a public pension reform that increased the statutory retirement age, or prolonged work participation beyond the retirement age, for older workers. Older workers was defined as age 45 and older, irrespective of whether younger age groups were also included in the analysis. Only studies that conformed to these criteria were retained.

\section{Inclusion Criteria}

Eligible studies reported either the effects of a public pension reform that increased the statutory retirement age or the effects of prolonged work participation beyond the retirement age for older workers. Both causal and non-causal empirical studies were included. Therefore, the population consisted of older workers of age 45 and older, irrespective of whether younger age groups were also included. The outcome was the effect on health, well-being, labor force participation, and the perception of the retirement age among older workers. We defined well-being as overall satisfaction, which also includes job satisfaction, quality of life, happiness, and stress. Labor force participation was defined as employment and engagement in paid labor. No distinction was made between voluntary and involuntary retirement. In the causal studies, the intervention was a public pension reform that increased the statutory retirement age, while there was no intervention in the non-causal studies, but these studies involved a prolonged work participation beyond the retirement age. No criteria for a control group, sector, or geographical area were formulated, nor were public pension reforms restricted to a timeframe.

\section{Exclusion Criteria}

Studies were excluded if they reported only outcomes on the meso- or macro-level, such as effects for the organization, labor market outcomes, or the sustainability of the old-age public pension program. Furthermore, studies were excluded if they did not explicitly investigate the relationship between an increase in the retirement age or working beyond the retirement age, with the outcomes. Studies that implicitly compared retirement ages, or studies that had a different research objective or question, were therefore excluded. Since this systematic literature review includes only empirical evidence, purely theoretical publications, book reviews, editorials, opinion papers, simulations, and evaluations were excluded. 


\section{Data Analysis}

We first assessed the quality of the included studies by reviewing the reliability and validity of these publications. The quality of the research design and the reported findings was assessed in line with Kampmeijer and colleagues (Kampmeijer et al. 2016). A study was considered reliable if there was a sound description of the utilized methods for data collection and analysis, and if these methods were repeatable (Kampmeijer et al. 2016). Furthermore, a study was considered valid if its results logically resulted from the research objective and methodology, and with the results presented in related publications (Kampmeijer et al. 2016). Studies that investigated causality were more likely to be graded as having a high validity. Irrespective of the quality assessment, all eligible papers were included in the analysis.

Because the included studies used various definitions, methods, and outcomes, we decided to perform a qualitative systematic literature review instead of a meta-analysis of the reported results. The text of the selected articles was analyzed using the method of directed qualitative content analysis (Hsieh and Shannon 2005), also known as thematic analysis. The study objectives were used to define the themes. Specifically, the following themes were used for data extraction: Authors, year of publication, country, change in retirement age, dataset used, data collection (year, horizon, and methods), included groups, total sample size, quality (reliability and validity) of studies, outcome variables, and the direction and magnitude of the effect. A deductive approach was used to extract the effects on the individual level.

Based on the themes, an extraction matrix was created. The relevant information extracted for each theme was synthesized and presented narratively. Tables were used to summarize results. Finally, we assessed the quality of our systematic literature review by applying the PRISMA checklist (Liberati et al. 2009; Moher et al. 2009) in Appendix 2.

\section{Results}

\section{Study Selection}

The process of study selection is outlined using the flow diagram in Fig. 1. A literature search using the search query, presented in Appendix 1, was performed in four databases and yielded 5780 initial results. The removal of 853 duplicates resulted in 4927 unique records.

In the first screening phase, 4610 records were excluded after reading the title of each article. Of the remaining 317 studies, 298 records were removed after reading the abstract in the second screening phase. For the third screening phase, the full texts of the remaining 19 publications were downloaded and read. Three publications were excluded because the full text indicated that these records were not relevant.

Subsequently, the remaining 16 publications were assessed for the inclusion criteria, such that only empirical studies were included. One purely theoretical publication and 


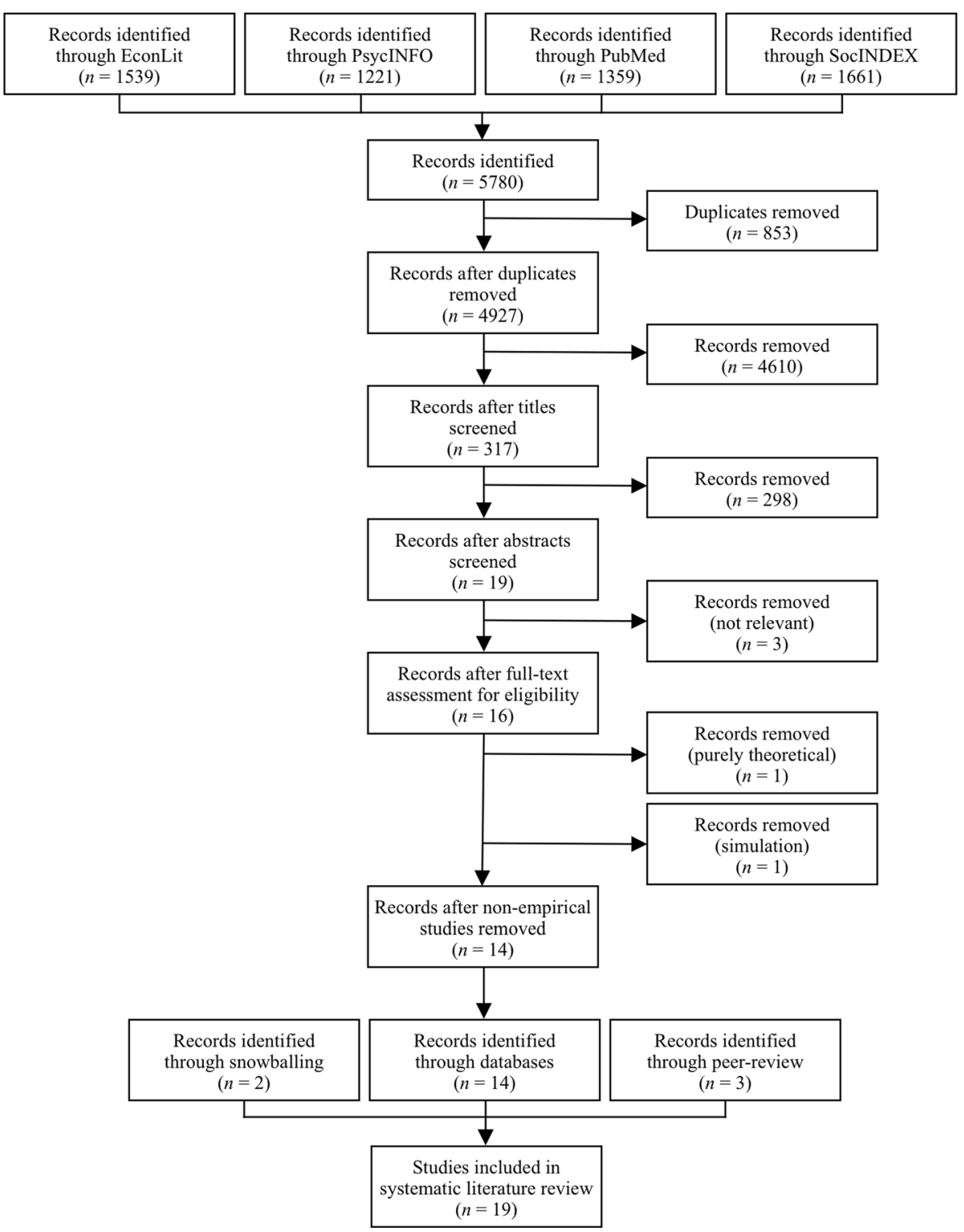

Fig. 1 Flow Diagram for Study Selection

one simulation study were excluded. Therefore, the study selection yielded 14 relevant studies through databases.

Furthermore, snowballing was performed by screening the reference lists of the remaining studies for relevant publications, which yielded two additional studies. In addition, based on the peer-review, three relevant studies were included as well.

Therefore, a total of 19 studies were included in this systematic literature review. Appendix 3 presents a detailed overview of these studies. 


\section{Study Characteristics}

A general description of the included studies is presented in Table 1. All studies were published between 2001 and 2019. A vast majority of these studies (89.5\%) was published after 2006, while $58.0 \%$ of the studies was published after 2014 .

In total, the studies utilized data from 23 countries. In most cases $(83.3 \%)$, the studies involved data from a country in the European Union (EU). The remaining countries were Israel (1.7\%), Switzerland (3.3\%), United Kingdom (8.3\%), and the United States $(3.3 \%)$. Data from Germany $(10.0 \%)$ and the Netherlands $(10.0 \%)$ were used most frequently.

Four methods for data collection were used. The most frequently utilized method was a survey $(52.6 \%)$, followed by administrative data $(21.1 \%)$ and matched administrative and survey data $(21.1 \%)$. Three of the four studies that used matched administrative and survey data were performed in the Netherlands, and used administrative data from a Dutch pension fund for public sector workers. An interview was only used in one study $(5.3 \%)$.

More than half of the studies $(52.7 \%)$ utilized data with a sample size less than 10,000 participants. Five studies $(26.3 \%$ ) had a sample size between 10,000 and 20,000 participants. In three studies $(15.8 \%$ ), the sample size was 20,000 or more. The study with the largest sample size had 936,251 participants. However, the sample size remained ambiguous in one study (5.3\%).

The quality of the included studies was assessed based on their reliability and validity. Almost half of the studies (47.4\%) had a high reliability and $47.4 \%$ had a medium reliability. Only one study (5.3\%) had a low reliability. In addition, $42.1 \%$ of the studies had a high validity and $52.6 \%$ had a medium validity. Only one study $(5.3 \%)$ had a low validity.

The studies reported 14 outcomes that were within the scope of this systematic literature review. Since studies could investigate more than one outcome simultaneously, these outcomes were studied 27 times in total. The three outcomes most studied are labor force participation (22.2\%), physical health (18.5\%), and mental health (14.8\%).

A summary of the characteristics of publications included in this study is presented in Table 2.

\section{Classification of Studies by Purpose of Investigation}

The studies appeared to have two distinct purposes of investigation (see Table 3). Twelve studies examined the effect of a public pension reform that increased the statutory retirement age among workers. In addition, seven studies were not directly related to an increased statutory retirement age, but instead investigated associations with prolonged labor force participation beyond the retirement age among workers. We use this binary classification to present the subsequent findings.

\section{Effects of Public Pension Reforms that Increased the Statutory Retirement Age}

The reported effects of public pension reforms that increased the statutory retirement age are summarized in Table 4. Twelve studies investigated the 
Table 1 General Description of Publications Included in the Analysis (19 Publications Reviewed)

\begin{tabular}{|c|c|c|c|}
\hline $\begin{array}{l}\text { Classification } \\
\text { Category }\end{array}$ & Sub-categories & $n(\%)$ & Studies \\
\hline \multirow{9}{*}{$\begin{array}{l}\text { Year of } \\
\text { publication }\end{array}$} & 2001 & $1(5.3)$ & (Choi 2001) \\
\hline & 2003 & $1(5.3)$ & (Mein et al. 2003) \\
\hline & 2006 & $2(10.5)$ & (Bellaby 2006; Bottazzi et al. 2006) \\
\hline & 2012 & $2(10.5)$ & (De Grip et al. 2012; Reynolds et al. 2012) \\
\hline & 2013 & $2(10.5)$ & $\begin{array}{l}\text { (De Grip et al. 2013; } \\
\quad \text { Staubli and Zweimüller 2013) }\end{array}$ \\
\hline & 2014 & $2(10.5)$ & (Horner 2014; Montizaan and Vendrik 2014) \\
\hline & 2017 & $4(21.1)$ & $\begin{array}{l}\text { (Demou et al. 2017; Engels et al. 2017; } \\
\text { Hess 2017; Wahrendorf et al. 2017) }\end{array}$ \\
\hline & 2018 & $4(21.1)$ & $\begin{array}{l}\text { (Bertoni et al. 2018; Hagen 2018; Hess 2018; } \\
\text { Shai 2018) }\end{array}$ \\
\hline & 2019 & $1(5.3)$ & (Geyer and Welteke 2019) \\
\hline \multirow[t]{19}{*}{ Country } & European Union (EU) & $50(83.3)$ & \\
\hline & Austria & $3(5.0)$ & $\begin{array}{l}\text { (Horner 2014; Staubli and Zweimüller 2013; } \\
\text { Wahrendorf et al. 2017) }\end{array}$ \\
\hline & Belgium & $3(5.0)$ & $\begin{array}{l}\text { (Hess 2017; Horner 2014; } \\
\text { Wahrendorf et al. 2017) }\end{array}$ \\
\hline & Czechia & $2(3.3)$ & (Horner 2014; Wahrendorf et al. 2017) \\
\hline & Denmark & $3(5.0)$ & $\begin{array}{l}\text { (Hess 2017; Horner 2014; } \\
\text { Wahrendorf et al. 2017) }\end{array}$ \\
\hline & Estonia & $1(1.7)$ & (Wahrendorf et al. 2017) \\
\hline & Finland & $1(1.7)$ & (Hess 2017) \\
\hline & France & $3(5.0)$ & $\begin{array}{l}\text { (Hess 2017; Horner 2014; } \\
\text { Wahrendorf et al. 2017) }\end{array}$ \\
\hline & Germany & $6(10.0)$ & $\begin{array}{l}\text { (Engels et al. 2017; Geyer and Welteke 2019; Hess } \\
\text { 2017, 2018; Horner 2014; } \\
\text { Wahrendorf et al. 2017) }\end{array}$ \\
\hline & Greece & $2(3.3)$ & (Hess 2017; Horner 2014) \\
\hline & Hungary & $1(1.7)$ & (Wahrendorf et al. 2017) \\
\hline & Ireland & $2(3.3)$ & (Hess, 2017; Horner, 2014) \\
\hline & Italy & $4(6.7)$ & $\begin{array}{l}\text { (Bertoni et al., 2018; Bottazzi et al. 2006; } \\
\text { Horner 2014; Wahrendorf et al. 2017) }\end{array}$ \\
\hline & Poland & $2(3.3)$ & (Horner 2014; Wahrendorf et al. 2017) \\
\hline & Portugal & $2(3.3)$ & (Hess 2017; Wahrendorf et al. 2017) \\
\hline & Scotland & $1(1.7)$ & (Demou et al. 2017) \\
\hline & Slovenia & $1(1.7)$ & (Wahrendorf et al. 2017) \\
\hline & Spain & $3(5.0)$ & $\begin{array}{l}\text { (Hess 2017; Horner 2014; } \\
\text { Wahrendorf et al. 2017) }\end{array}$ \\
\hline & Sweden & $4(6.7)$ & $\begin{array}{l}\text { (Hagen 2018; Hess, 2017; Horner 2014; } \\
\text { Wahrendorf et al. 2017) }\end{array}$ \\
\hline
\end{tabular}


Table 1 (continued)

Classification Sub-categories $\quad n(\%) \quad$ Studies
Category

\begin{tabular}{|c|c|c|c|}
\hline & The Netherlands & $6(10.0)$ & $\begin{array}{l}\text { (De Grip et al. 2012, 2013; } \\
\text { Hess 2017; Horner 2014; } \\
\text { Montizaan and Vendrik 2014; } \\
\text { Wahrendorf et al. 2017) }\end{array}$ \\
\hline & Israel & $1(1.7)$ & (Shai 2018) \\
\hline & Switzerland & $2(3.3)$ & (Horner 2014; Wahrendorf et al. 2017) \\
\hline & United Kingdom & $5(8.3)$ & $\begin{array}{l}\text { (Bellaby 2006; Hess 2017; Horner 2014; } \\
\text { Mein et al. 2003; Reynolds et al. 2012) }\end{array}$ \\
\hline & United States & $2(3.3)$ & (Choi 2001; Horner 2014) \\
\hline \multirow{4}{*}{$\begin{array}{l}\text { Method for } \\
\text { data } \\
\text { collection }\end{array}$} & Administrative data & $4(21.1)$ & $\begin{array}{l}\text { (Engels et al. 2017; Geyer and Welteke 2019; } \\
\text { Hagen 2018; Staubli and Zweimüller 2013) }\end{array}$ \\
\hline & Interview & $1(5.3)$ & (Reynolds et al. 2012) \\
\hline & $\begin{array}{l}\text { Matched administrative and } \\
\text { survey data }\end{array}$ & $4(21.1)$ & $\begin{array}{l}\text { (Choi 2001; De Grip et al. 2012, 2013; } \\
\text { Montizaan and Vendrik 2014) }\end{array}$ \\
\hline & Survey(s) & $10(52.6)$ & $\begin{array}{l}\text { (Bellaby 2006; Bertoni et al. 2018; } \\
\text { Bottazzi et al. 2006; Demou et al. 2017; } \\
\text { Hess 2017, 2018; Horner 2014; } \\
\text { Mein et al. 2003; Shai 2018; } \\
\text { Wahrendorf et al. 2017) }\end{array}$ \\
\hline \multirow[t]{6}{*}{ Sample size } & Less than 5000 & $6(31.6)$ & $\begin{array}{l}\text { (Choi 2001; De Grip et al. 2013; Geyer and } \\
\text { Welteke 2019; Hess 2018; Mein et al. 2003; } \\
\text { Reynolds et al. 2012) }\end{array}$ \\
\hline & 5000 to 9999 & $4(21.1)$ & $\begin{array}{l}\text { (Bellaby 2006; Bertoni et al. 2018; De Grip et al. } \\
\text { 2012; Hess 2017) }\end{array}$ \\
\hline & 10,000 to 14,999 & $2(10.5)$ & (Demou et al. 2017; Montizaan and Vendrik 2014) \\
\hline & 15,000 or 19,999 & $3(15.8)$ & $\begin{array}{l}\text { (Bottazzi et al. 2006; Horner 2014; Wahrendorf } \\
\text { et al. 2017) }\end{array}$ \\
\hline & 20,000 or more & $3(15.8)$ & $\begin{array}{l}\text { (Engels et al. 2017; Hagen 2018; Staubli and } \\
\text { Zweimüller 2013) }\end{array}$ \\
\hline & Unknown & $1(5.3)$ & (Shai 2018) \\
\hline \multirow[t]{3}{*}{ Reliability } & Low & $1(5.3)$ & (Reynolds et al. 2012) \\
\hline & Medium & $9(47.4)$ & $\begin{array}{l}\text { (Bellaby 2006; Bottazzi et al. 2006; Choi 2001; } \\
\text { Demou et al. 2017; Engels et al. 2017; Hess } \\
\text { 2018; Mein et al. 2003; Staubli and Zweimüller } \\
\text { 2013; Wahrendorf et al. 2017) }\end{array}$ \\
\hline & High & $9(47.4)$ & $\begin{array}{l}\text { (Bertoni et al. 2018; De Grip et al. 2012, 2013; } \\
\text { Geyer and Welteke 2019; Hagen 2018; Hess } \\
\text { 2017; Horner 2014; Montizaan and Vendrik } \\
\text { 2014; Shai 2018) }\end{array}$ \\
\hline \multirow[t]{2}{*}{ Validity } & Low & $1(5.3)$ & (Reynolds et al. 2012) \\
\hline & Medium & $10(52.6)$ & $\begin{array}{l}\text { (Bellaby 2006; Choi, 2001; Demou et al. 2017; } \\
\text { Engels et al. 2017; Hess, 2017, 2018; Horner } \\
\text { 2014; Mein et al. 2003; Staubli and Zweimüller } \\
\text { 2013; Wahrendorf et al. 2017) }\end{array}$ \\
\hline
\end{tabular}


Table 1 (continued)

\begin{tabular}{|c|c|c|c|}
\hline $\begin{array}{l}\text { Classification } \\
\text { Category }\end{array}$ & Sub-categories & $n(\%)$ & Studies \\
\hline & High & $8(42.1)$ & $\begin{array}{l}\text { (Bertoni et al. 2018; Bottazzi et al. 2006; De Grip } \\
\text { et al. 2012, 2013; Geyer and Welteke 2019; } \\
\text { Hagen 2018; Montizaan and Vendrik 2014; Shai } \\
\text { 2018) }\end{array}$ \\
\hline \multirow[t]{14}{*}{ Outcome } & $\begin{array}{l}\text { Discrepancy between } \\
\text { expected and preferred } \\
\text { retirement ages }\end{array}$ & $1(3.7)$ & (Hess 2018) \\
\hline & Expected retirement age & $2(7.4)$ & (Bottazzi et al. 2006; De Grip et al. 2013) \\
\hline & Job satisfaction & $1(3.7)$ & (Montizaan and Vendrik 2014) \\
\hline & Health inequalities & $1(3.7)$ & (Bellaby 2006) \\
\hline & Health promoting behaviors & $1(3.7)$ & (Bertoni et al. 2018) \\
\hline & Labor force participation & $6(22.2)$ & $\begin{array}{l}\text { (Demou et al. 2017; Engels et al. 2017; Geyer and } \\
\text { Welteke 2019; Hagen 2018; Shai 2018; Staubli } \\
\text { and Zweimüller 2013) }\end{array}$ \\
\hline & Life satisfaction & $1(3.7)$ & (Choi 2001) \\
\hline & Mental health & $4(14.8)$ & $\begin{array}{l}\text { (De Grip et al. 2012; Mein et al. 2003; Reynolds } \\
\text { et al. 2012; Wahrendorf et al. 2017) }\end{array}$ \\
\hline & Physical health & $5(18.5)$ & $\begin{array}{l}\text { (Bertoni et al. 2018; Mein et al. 2003; Reynolds } \\
\text { et al. 2012; Shai 2018; Wahrendorf et al. 2017) }\end{array}$ \\
\hline & Preferred retirement age & $1(3.7)$ & (Hess 2017) \\
\hline & Satisfaction with health & $1(3.7)$ & (Bertoni et al. 2018) \\
\hline & Subjective well-being & $1(3.7)$ & (Horner 2014) \\
\hline & Utilization of healthcare & $1(3.7)$ & (Hagen 2018) \\
\hline & Work stress & $1(3.7)$ & (Wahrendorf et al. 2017) \\
\hline
\end{tabular}

The sum of $n$ per classification category can be greater than 19 papers because each publication can be categorized in multiple sub-categories.

impact of public pension reforms on 10 specific outcomes, namely the expected retirement age, health inequalities, health promoting behaviors, job satisfaction, labor force participation, mental health, physical health, preferred retirement age, satisfaction with health, and utilization of healthcare.

These outcomes were clustered into three groups (see Table 5). The first group is health. This includes health inequalities, health promoting behaviors, mental health, physical health, satisfaction with health, and utilization of healthcare. The second group is well-being and was operationalized to include job satisfaction as well. The third group is labor force participation and perception of retirement ages. This includes the expected retirement age, labor force participation, and preferred retirement age. We discuss the findings of these outcomes below. 


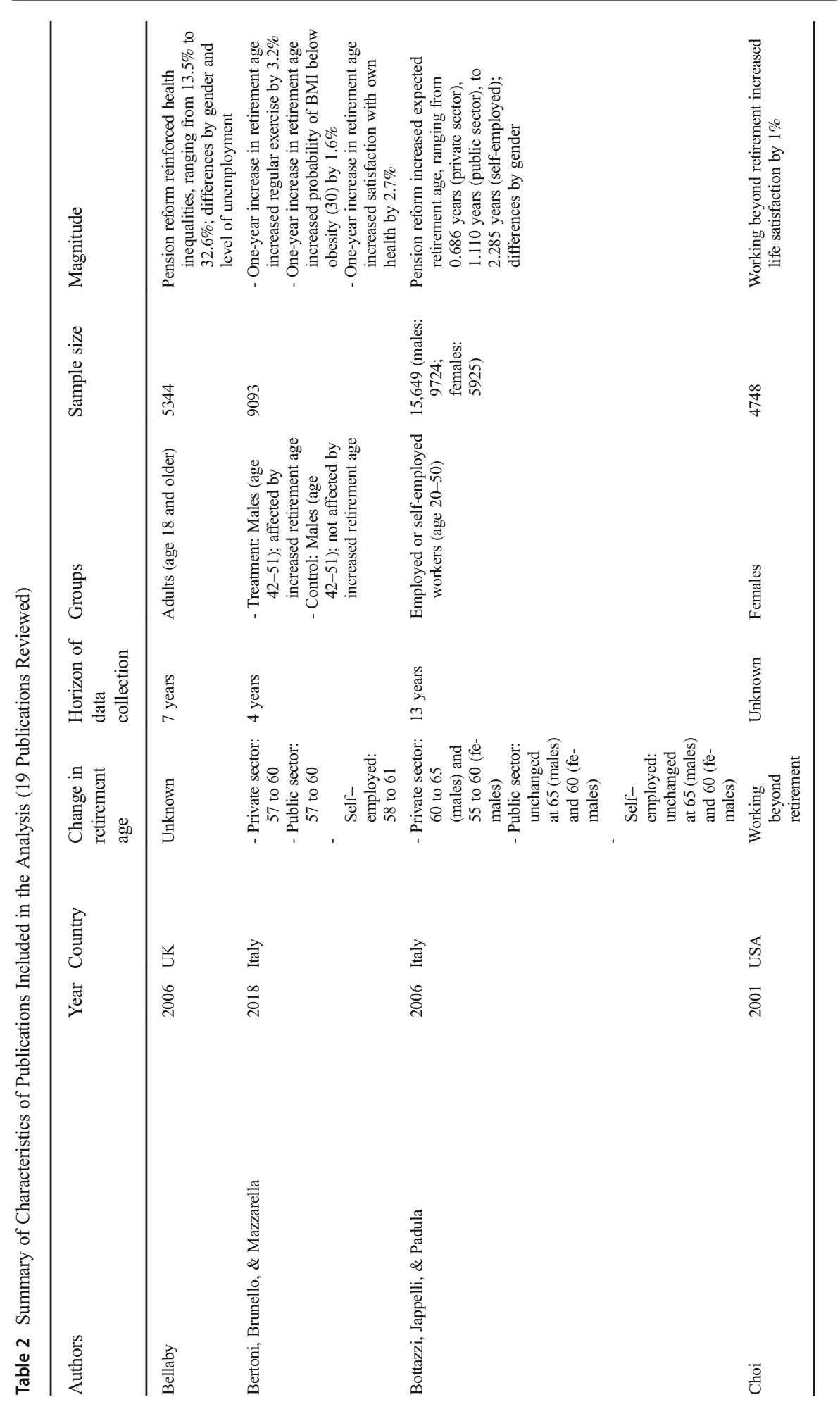




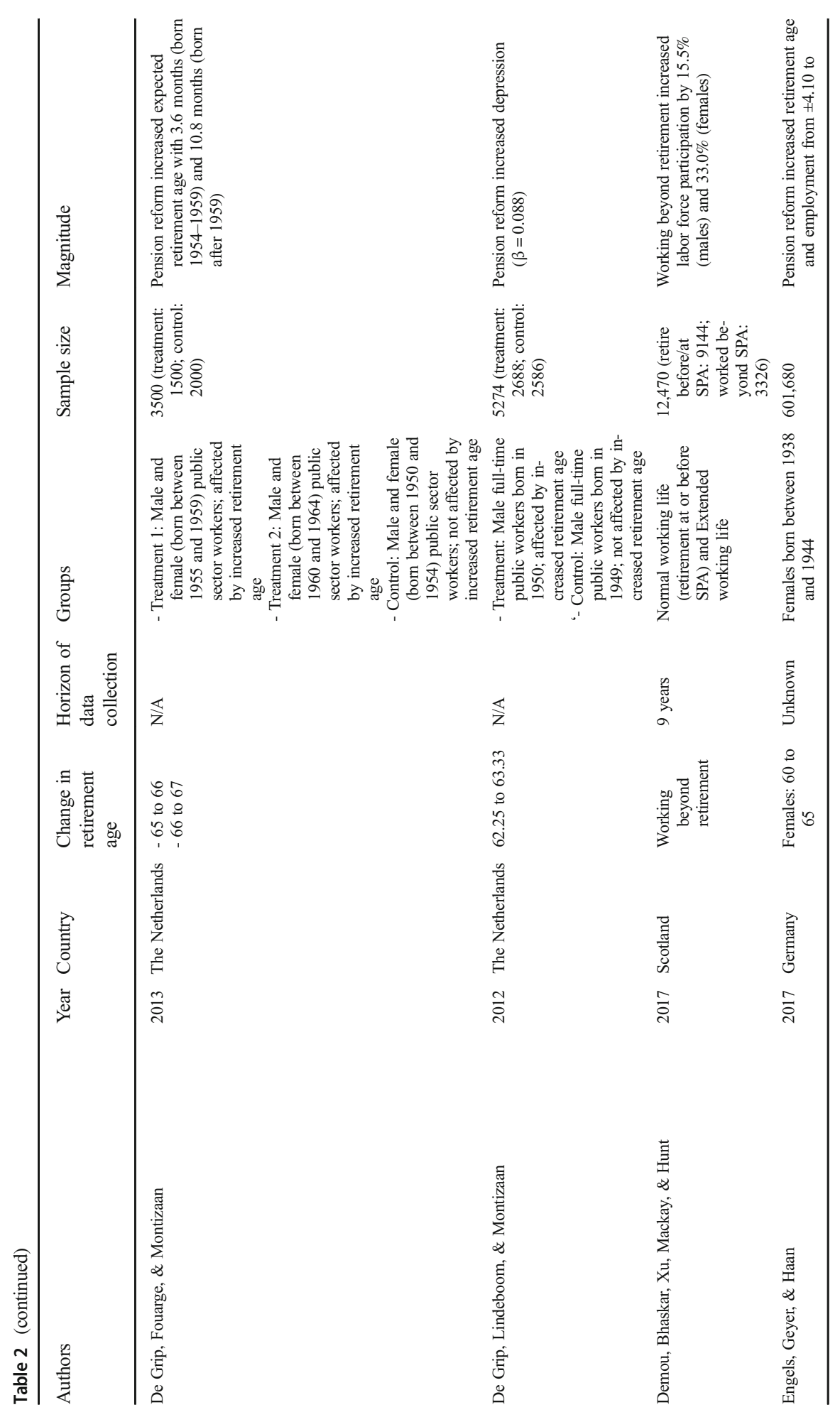




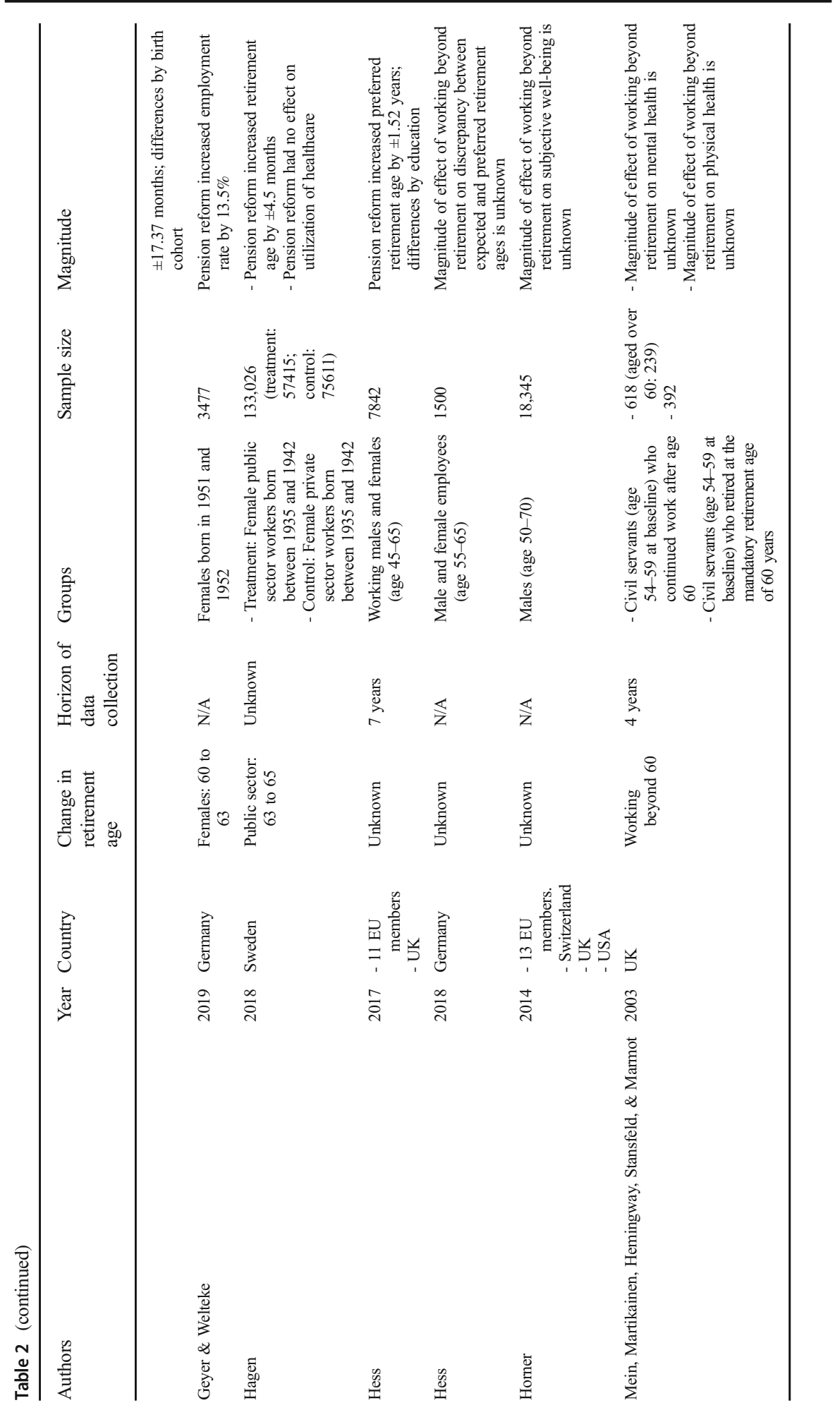




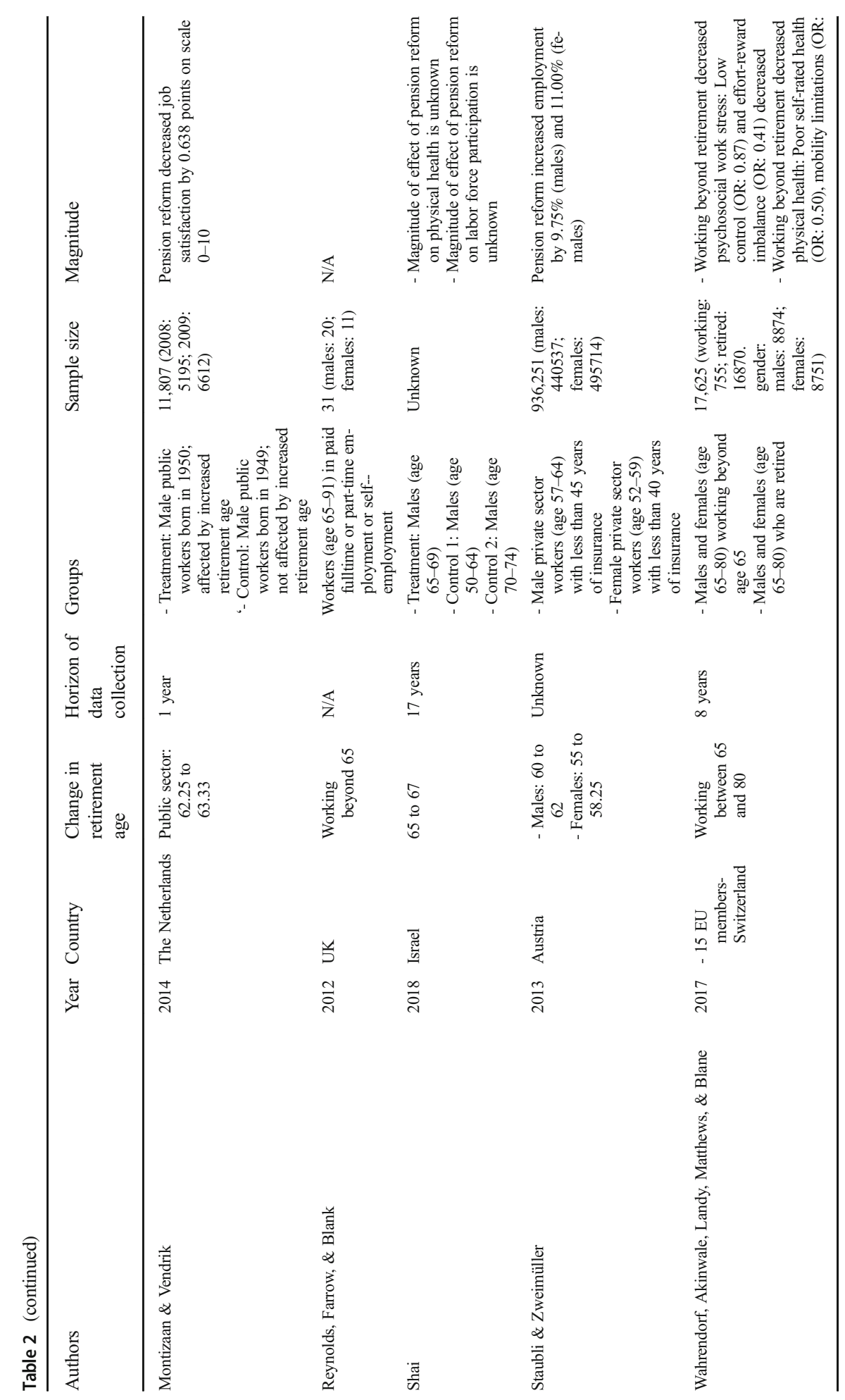




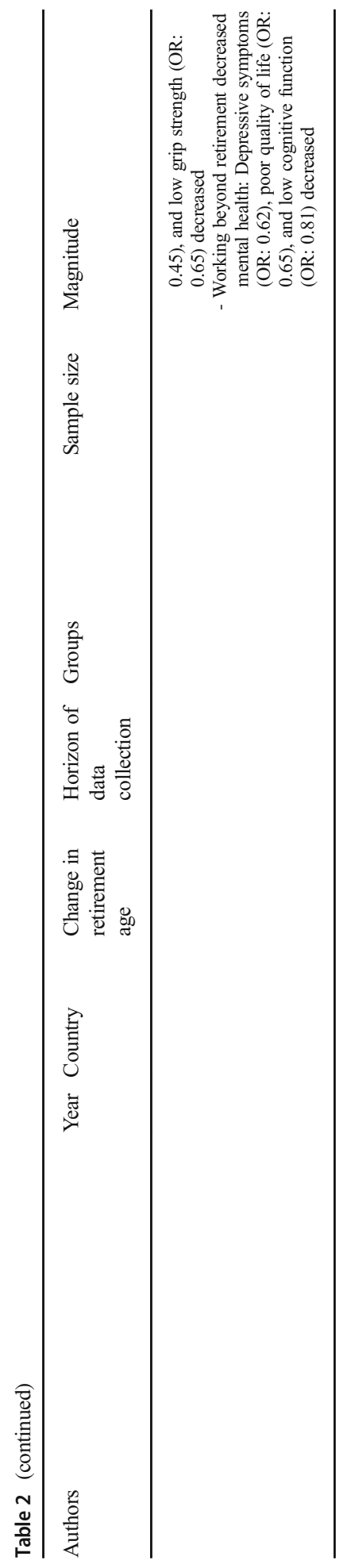

을 Springer 
Table 3 Publications by Purpose of Investigation (19 Publications Reviewed)

\begin{tabular}{|c|c|c|}
\hline Purpose of Investigation & Authors & Year \\
\hline \multirow[t]{12}{*}{ Increased statutory retirement age } & Bellaby & 2006 \\
\hline & Bertoni, Brunello, \& Mazzarella & 2018 \\
\hline & Bottazzi, Jappelli, \& Padula & 2006 \\
\hline & De Grip, Fouarge, \& Montizaan & 2013 \\
\hline & De Grip, Lindeboom, \& Montizaan & 2012 \\
\hline & Engels, Geyer, \& Haan & 2017 \\
\hline & Geyer \& Welteke & 2019 \\
\hline & Hagen & 2018 \\
\hline & Hess & 2017 \\
\hline & Montizaan \& Vendrik & 2014 \\
\hline & Shai & 2018 \\
\hline & Staubli \& Zweimüller & 2013 \\
\hline \multirow[t]{7}{*}{ Working beyond the retirement age } & Choi & 2001 \\
\hline & Demou, Bhaskar, Xu, Mackay, \& Hunt & 2017 \\
\hline & Hess & 2018 \\
\hline & Horner & 2014 \\
\hline & Mein, Martikainen, Hemingway, Stansfeld, \& Marmot & 2003 \\
\hline & Reynolds, Farrow, \& Blank & 2012 \\
\hline & Wahrendorf, Akinwale, Landy, Matthews, \& Blane & 2017 \\
\hline
\end{tabular}

\section{Effect on Health}

The majority of studies $(60.0 \%)$ reported a significant negative effect on health, while the remaining studies reported either no effect (20.0\%) or significant positive effect (20.0\%).

A public pension reform that increased the statutory retirement age was found to reinforce health inequalities by $13.5 \%$ to $32.6 \%$ (Bellaby 2006). Health inequalities by gender, social class, and geographical area in the United Kingdom were found to increase after the statutory retirement age was increased (Bellaby 2006). This is problematic, because especially the health of the disadvantaged and lower-paid workers appeared to be sensitive to later retirement (Bellaby 2006).

A public pension reform that increased the retirement age in the Netherlands had a strong deteriorating effect on the mental health $(\beta=0.088)$ of older male civil workers before they retired (De Grip et al. 2012). Mental health was measured by symptoms of depression (De Grip et al. 2012). The authors reported that income may moderate this effect, because workers who lost more income, or those having a partner without an income, perceived a stronger deterioration of their mental health due to the pension reform (De Grip et al. 2012). This study suggests that delaying the eligibility to pension benefits, in combination with having limited alternative financial resources, strengthens negative thoughts about one's social security. 
Table 4 Outcomes of Increased Statutory Retirement Age and Working Beyond the Retirement Age Reported in the Publications Included in the Analysis (19 Publications Reviewed)

\begin{tabular}{|c|c|c|c|}
\hline & & Increased Statutory Retirement Age $(n=12)$ & $\begin{array}{l}\text { Working Beyond the } \\
\text { Retirement Age } \\
(n=7)\end{array}$ \\
\hline Outcome & Influence & Studies & Studies \\
\hline \multirow{3}{*}{$\begin{array}{l}\text { Discrepancy between } \\
\text { expected and preferred } \\
\text { retirement ages }\end{array}$} & Negative & - & (Hess 2018) \\
\hline & Neutral & - & - \\
\hline & Positive & - & - \\
\hline \multirow[t]{3}{*}{ Expected retirement age } & Negative & - & - \\
\hline & Neutral & - & - \\
\hline & Positive & (Bottazzi et al. 2006; De Grip et al. 2013) & - \\
\hline \multirow[t]{3}{*}{ Health inequalities ${ }^{\dagger}$} & Negative & - & - \\
\hline & Neutral & - & - \\
\hline & Positive & (Bellaby 2006) & - \\
\hline \multirow{3}{*}{$\begin{array}{l}\text { Health promoting } \\
\text { behaviors }\end{array}$} & Negative & - & - \\
\hline & Neutral & - & - \\
\hline & Positive & (Bertoni et al. 2018) & - \\
\hline \multirow[t]{3}{*}{ Job satisfaction } & Negative & (Montizaan and Vendrik 2014) & - \\
\hline & Neutral & - & - \\
\hline & Positive & - & - \\
\hline \multirow[t]{3}{*}{ Labor force participation } & Negative & - & - \\
\hline & Neutral & - & - \\
\hline & Positive & $\begin{array}{l}\text { (Engels et al. 2017; Geyer and Welteke 2019; } \\
\text { Hagen 2018; Shai 2018; Staubli and } \\
\text { Zweimüller 2013) }\end{array}$ & (Demou et al. 2017) \\
\hline \multirow[t]{3}{*}{ Life satisfaction } & Negative & - & - \\
\hline & Neutral & - & (Choi 2001) \\
\hline & Positive & - & - \\
\hline \multirow[t]{3}{*}{ Mental health } & Negative & (De Grip et al. 2012) & (Mein et al. 2003) \\
\hline & Neutral & - & - \\
\hline & Positive & - & $\begin{array}{l}\text { (Reynolds et al. } \\
\text { 2012; Wahrendorf } \\
\text { et al. 2017) }\end{array}$ \\
\hline \multirow[t]{3}{*}{ Physical health } & Negative & (Shai, 2018) & - \\
\hline & Neutral & - & (Mein et al. 2003) \\
\hline & Positive & (Bertoni et al. 2018) & $\begin{array}{l}\text { (Reynolds et al. } \\
\text { 2012; Wahrendorf } \\
\text { et al. 2017) }\end{array}$ \\
\hline \multirow[t]{3}{*}{ Preferred retirement age } & Negative & - & - \\
\hline & Neutral & - & - \\
\hline & Positive & (Hess 2017) & - \\
\hline Satisfaction with health & Negative & - & - \\
\hline
\end{tabular}


Table 4 (continued)

Increased Statutory Retirement Age $(n=12) \quad$ Working Beyond the Retirement Age

$(n=7)$

\begin{tabular}{lll}
\hline Outcome & Influence Studies & Studies \\
\hline & Neutral - & - \\
& Positive (Bertoni et al. 2018) & - \\
Subjective well-being & Negative - & (Horner 2014) \\
& Neutral - & - \\
Utilization of healthcare & Positive - & - \\
& Negative - & - \\
& Neutral (Hagen 2018) & - \\
Positive - & - \\
& Negative - & - \\
& Neutral - & Wahrendorf et al. \\
& Positive - & 2017)
\end{tabular}

The sum of $n$ per outcome can be greater than either 12 or 7 papers because each publication can be categorized by multiple influences.

${ }^{\dagger}$, Although a positive effect was reported on health inequalities, a reinforcement of health inequalities has a negative effect on the health of older workers.

After a public pension reform, physical health deteriorated by one standard deviation among Israeli workers who continued labor force participation beyond the age of 64 (Shai 2018). The authors indicated that the health of blue-collar workers and lesseducated who often perform physically demanding work, was affected most (Shai 2018).

In addition, $20.0 \%$ of the studies round no evidence that the pension reform affects health. These studies looked at the use of healthcare. Utilization of healthcare involved, among others, hospitalization and prescriptions for drugs (Hagen 2018). The author concludes that delaying the entitlement to pension benefits has no significant short-term effect on public healthcare expenditure (Hagen 2018).

However, $20.0 \%$ of the studies reported a significant positive effect of the pension reform on health, operationalized by health promoting behaviors, physical health, and satisfaction with health. The increased statutory retirement age positively affected health promoting behaviors, physical health, and satisfaction with health, prior to the actual retirement of workers in Italy (Bertoni et al. 2018). For example, a one-year increase of compulsory labor force participation increased the probability of engaging in regular exercise by $3.2 \%$ (Bertoni et al. 2018). Furthermore, the likelihood of a reduction in BMI below obesity and satisfaction with own health increased by $1.6 \%$ and $2.7 \%$, respectively (Bertoni et al. 2018). This suggests that workers may anticipate to prolong their working life by adopting health-promoting behaviors that facilitate them to continue labor force participation until an older age (Bertoni et al. 2018). 
Table 5 Categories of Outcomes Reported in the Publications (19 Publications Reviewed)

\begin{tabular}{|c|c|c|c|c|c|}
\hline \multirow[b]{2}{*}{ Outcome category } & \multirow[b]{2}{*}{ Influence } & \multicolumn{2}{|c|}{ Increased Statutory Retirement Age $(n=12)$} & \multicolumn{2}{|c|}{$\begin{array}{l}\text { Working Beyond the } \\
\text { Retirement Age }(n=7)\end{array}$} \\
\hline & & $n(\%)$ & Studies & $n(\%)$ & Studies \\
\hline \multirow[t]{3}{*}{ Health } & Negative & $3(60.0)$ & $\begin{array}{l}\text { (Bellaby 2006; De Grip et al. 2012; } \\
\text { Shai 2018) }\end{array}$ & $1(25.0)$ & $\begin{array}{l}\text { (Mein et al. } \\
\text { 2003) }\end{array}$ \\
\hline & Neutral & $1(20.0)$ & (Hagen 2018) & $1(25.0)$ & $\begin{array}{l}\text { (Mein et al. } \\
\text { 2003) }\end{array}$ \\
\hline & Positive & $1(20.0)$ & (Bertoni et al. 2018) & $2(50.0)$ & $\begin{array}{l}\text { (Reynolds et al. } \\
\text { 2012; } \\
\text { Wahrendorf } \\
\text { et al. 2017) }\end{array}$ \\
\hline \multirow[t]{3}{*}{ Well-being } & Negative & $1(100.0)$ & (Montizaan and Vendrik 2014) & $0(0.0)$ & - \\
\hline & Neutral & $0(0.0)$ & - & $2(66.7)$ & $\begin{array}{l}\text { (Choi 2001; } \\
\text { Horner, } \\
\text { 2014) }\end{array}$ \\
\hline & Positive & $0(0.0)$ & - & $1(33.3)$ & $\begin{array}{l}\text { (Wahrendorf } \\
\text { et al. 2017) }\end{array}$ \\
\hline \multirow{3}{*}{$\begin{array}{l}\text { Labor force } \\
\text { participation and } \\
\text { Perception of } \\
\text { retirement ages }\end{array}$} & Negative & $0(0.0)$ & - & $1(50.0)$ & (Hess 2018) \\
\hline & Neutral & $0(0.0)$ & - & $0(0.0)$ & - \\
\hline & Positive & $8(100.0)$ & $\begin{array}{l}\text { (Bottazzi et al. 2006; De Grip et al. } \\
\text { 2013; Engels et al. 2017;Geyer } \\
\text { and Welteke 2019; Hagen 2018; } \\
\text { Hess 2017; Shai 2018; Staubli } \\
\text { and Zweimüller 2013) }\end{array}$ & $1(50.0)$ & $\begin{array}{l}\text { (Demou et al. } \\
\text { 2017) }\end{array}$ \\
\hline
\end{tabular}

Category Health includes the outcomes: Health inequalities (codes as negative), health promoting behaviors, mental health, physical health, satisfaction with health, and utilization of healthcare.

Category Well-being includes the outcomes: Job satisfaction, life satisfaction, subjective well-being, and work stress.

Category Labor force participation and Perception of retirement ages includes the outcomes: Discrepancy between expected and preferred retirement ages, expected retirement age, labor force participation, and preferred retirement age.

The sum of $n$ per outcome category can be greater than either 12 or 7 papers because each publication can be categorized by multiple influences.

\section{Effect on Well-Being}

We investigated the evidence about the effect of a public pension reform that increased the statutory retirement age on well-being. Only one publication studied the effect on job satisfaction.

The job satisfaction of Dutch older male public sector workers deteriorated as a result of a public pension reform (Montizaan and Vendrik 2014). Specifically, job satisfaction, measured on a scale from 0 to 10 , decreased by 0.638 points as a result of the pension reform (Montizaan and Vendrik 2014). This negative effect was explained by social comparison with colleagues; the prolonged labor force participation was perceived as unfair compared to workers who were not obligated to retire later (Montizaan and Vendrik 2014). 


\section{Effect on Labor Force Participation and Perception of Retirement Age}

We assessed the evidence about the effect of a public pension reform that increased the statutory retirement age on labor force participation and the perception of the retirement age. All included studies reported a significant positive effect on the expected retirement age, preferred retirement age, and labor force participation.

Two studies among Dutch and Italian workers respectively, reported that the announcement of a public pension reform that increased the statutory retirement age stimulated workers to change their expected retirement age in the direction of the public pension reform (Bottazzi et al. 2006; De Grip et al. 2013). First, in the Italian study, the pension reform resulted in an increase of the expected retirement age ranging from 0.686 years (private sector) and 1.110 years (public sector), to 2.285 years for self-employed (Bottazzi et al. 2006). These increases differed by gender (Bottazzi et al. 2006). Second, in the Dutch study, the pension reform resulted in an increase of the expected retirement age by 3.6 months (born 19541959) to 10.8 months (born after 1959) (De Grip et al. 2013). Furthermore, the expected retirement age increased most for females compared to males, which the author explained by an income effect (De Grip et al. 2013). The authors also found no evidence among couples that an increase of the statutory retirement age for one partner had influenced the retirement expectations of the other partner (De Grip et al. 2013). In addition, the increase of the expected retirement age was higher among highly-educated workers, while lower-educated workers or those performing physically demanding work were less affected (De Grip et al. 2013).

Similarly, a study in twelve European countries (i.e. Belgium, Denmark, Finland, France, Germany, Greece, Ireland, Portugal, Spain, Sweden, the Netherlands, and the United Kingdom) reported that the preferred retirement age increased by an average of 1.5 years after a public pension reform that increased the statutory retirement age took effect (Hess 2017). However, the increase of the preferred retirement age was weaker for lower-educated workers, suggesting that predominantly higher-educated workers preferred later retirement (Hess 2017).

Furthermore, the public pension reform increased the labor force participation of workers (Engels et al., 2017; Geyer and Welteke 2019; Hagen 2018; Shai 2018; Staubli and Zweimüller 2013).

Two German studies that utilized administrative data on females concluded that an increase in the retirement age had indeed increased employment rates among older workers and had delayed their retirement (Engels et al. 2017; Geyer and Welteke 2019). First, one study reported that the pension reform resulted in an increase of the retirement age and employment by approximately 4.10 to 17.37 months, but differences were found between birth cohorts (Engels et al. 2017). Second, another study reported that the pension reform increased the employment rate by 13.5\% (Geyer and Welteke 2019).

After Sweden increased the retirement age for workers in the public sector from 63 to 65 , a study investigated the effects of this increase on labor force participation (Hagen 2018). The study compared females born between 1935 and 1942, where the treatment group involved public sector workers and the control group involved private sector workers that were not affected by this policy reform (Hagen 2018). The author 
concludes that, on average, female public sector workers retired 4.5 months later (Hagen 2018).

After a public pension reform that increased the retirement age in Israel, one study reported that the actual labor force participation of older male workers increased from $37 \%$ before the pension reform, to $47 \%$ after the pension reform (Shai 2018).

Another study investigated the effectiveness of a policy reform that delayed eligibility to pension benefits to reduce unemployment among older workers (Staubli and Zweimüller 2013). This Austrian study utilized the exogenous pension reform where the retirement age was increased from 60 to 62 years for males, and from 55 to 58.25 years for females (Staubli and Zweimüller 2013). Administrative data were used to investigate the hypothesized effects among private sector workers (Staubli and Zweimüller 2013). The authors conclude that this policy reform had indeed increased employment among males by $9.75 \%$ and females by $11.0 \%$ (Staubli and Zweimüller 2013).

\section{Outcomes of Studies on Working beyond the Retirement Age}

The reported outcomes of working beyond the retirement age are summarized in Table 4. Seven studies investigated the relationship between working beyond the retirement age with seven specific outcomes.

These outcomes were clustered into three groups (see Table 5). The first group is health. This includes mental health and physical health. The second group is wellbeing, which includes life satisfaction, subjective well-being, and work stress. The third group is labor force participation and perception of retirement age. This includes the discrepancy between expected and preferred retirement ages, and labor force participation. We discuss the findings of the outcomes below.

\section{Outcomes for Health}

We assessed the evidence about the relation between working beyond the statutory retirement age and mental health and physical health. Some studies reported significant negative $(25.0 \%)$ or neutral $(25.0 \%)$ outcomes, while $50.0 \%$ of the studies reported significant positive outcomes for health.

Three studies reported different findings regarding mental health, where one study reported negative outcomes (Mein et al. 2003) and two studies reported positive outcomes (Reynolds et al. 2012; Wahrendorf et al. 2017). One British study found that mental health deteriorated among older civil servants who continued labor force participation beyond the retirement age of 60 (Mein et al. 2003). Although limited to the higher employment levels, once these workers retired, their mental health improved again (Mein et al. 2003). In contrast, another qualitative British study reported that continued labor force participation beyond retirement facilitated them to maintain their mental health (Reynolds et al. 2012). Similarly, a study conducted in 16 European countries (i.e. Austria, Belgium, Czechia, Denmark, Estonia, France, Germany, Hungary, Italy, Poland, Portugal, Slovenia, Spain, Sweden, Switzerland, and the Netherlands) reported that older males and females who worked beyond the age of 65 had a better mental health than those who had already retired (Wahrendorf et al. 2017). Mental health was 
measured by depressive symptoms, poor quality of health, and low cognitive functioning (Wahrendorf et al. 2017).

Two studies reported positive outcomes for physical health (Reynolds et al. 2012; Wahrendorf et al. 2017), while one study reported neutral outcomes (Mein et al. 2003). A British qualitative study among older workers reported that continued labor force participation beyond retirement facilitated them to maintain their physical health (Reynolds et al. 2012). Another large European study conducted in 16 European countries (i.e. Austria, Belgium, Czechia, Denmark, Estonia, France, Germany, Hungary, Italy, Poland, Portugal, Slovenia, Spain, Sweden, Switzerland, and the Netherlands) found that older males and females who worked beyond the age of 65 had better physical health than those who had already retired (Wahrendorf et al. 2017). Physical health was measured by poor self-rated health, limitations in mobility, and low grip strength (Wahrendorf et al. 2017). In contrast, a British study among older civil servants found that physical health deteriorated both for workers who continued to work after the statutory retirement age of 60 and for those who had retired, and that this deterioration was not related to retirement at the age of 60 (Mein et al. 2003).

\section{Outcomes for Well-Being}

We investigated the evidence about the relation between working beyond the statutory retirement age and life satisfaction, subjective well-being, and work stress. Three studies were published on this subject. These studies reported significant positive $(33.3 \%)$ and neutral $(66.6 \%)$ outcomes for well-being.

Working beyond the statutory retirement age resulted in better psychosocial working conditions (i.e. work stress) (Wahrendorf et al. 2017). A large European study conducted in 16 European countries (i.e. Austria, Belgium, Czechia, Denmark, Estonia, France, Germany, Hungary, Italy, Poland, Portugal, Slovenia, Spain, Sweden, Switzerland, and the Netherlands) reported that older males and females who worked beyond the age of 65 had better psychosocial working conditions than retired persons had during their last job before retirement (Wahrendorf et al. 2017). In this study, psychosocial work stress was measured as low control and effort-reward imbalance (Wahrendorf et al. 2017). In contrast, another study reported that later retirement did not result in higher life satisfaction among females in the United States, but instead the author hypothesized that reduced financial distress resulting from this stream of financial income may instead increase life satisfaction (Choi 2001). In addition, another large study conducted in Europe (i.e. Austria, Belgium, Czechia, Denmark, France, Germany, Greece, Ireland, Italy, Poland, Spain, Sweden, Switzerland, the Netherlands, and the United Kingdom) and the United States reported that working beyond the retirement age had no clear association with subjective well-being, compared to workers who retired earlier (Horner 2014). The authors also reported that, while subjective well-being initially improved upon retirement, still a strong deterioration of subjective well-being occurred several years later (Horner 2014).

\section{Outcomes for Labor Force Participation and Perception of Retirement Ages}

We assessed the evidence on a relation of working beyond the statutory retirement age with labor force participation and the perception of the retirement ages. The perception 
of the retirement age was measured as the discrepancy between the expected and preferred retirement ages. Two studies were published on this subject, where $50.0 \%$ of studies reported a significant positive relation, and $50.0 \%$ reported significant negative relation.

There was a positive relation with labor force participation (Demou et al. 2017). A large study conducted in Scotland reported that males and females increased their labor force participation to a higher age (Demou et al. 2017). Specifically, the labor force participation increased by $15.5 \%$ among males and $33.0 \%$ among females. Interestingly, predominantly women extended their working lives, which the authors attributed to a lower former threshold for the eligibility to public pension benefits for females (Demou et al. 2017).

Instead, Hess (2018) observed a discrepancy between the expected and preferred retirement ages by older male and female workers in Germany. These workers preferred to retire 1.75 years earlier than their expected retirement age Hess (2018). In addition, Hess (2018) found that in Germany, the preference toward retirement timing may be subject to social inequality. Specifically, the difference between the expected and preferred retirement ages was significantly larger for workers who were lower-educated, had less income, or had a lower job level (Hess 2018).

\section{Discussion}

The purpose of this systematic literature review was to investigate the evidence on what the effects are of an increase of the retirement age on the health, well-being, and labor force participation of older workers. This review is relevant because many countries have increased their statutory retirement age and delayed the age of eligibility to pension benefits, while there continues to exist an ongoing discussion about the effects of such policy reform.

\section{Comparison Sof Outcomes of Public Pension Reforms and Working beyond the Retirement Age}

Overall, the included studies that investigated the effects of a public pension reform that increased the statutory retirement age and studies that examined the outcomes of working beyond the retirement age, illustrate that inconclusive evidence exists regarding the effect on the health of older workers. Health was often operationalized differently, which makes a sound comparison of these results difficult. An increase in the retirement age had a positive effect on health promoting behaviors and satisfaction with health, no effect was reported on the utilization of healthcare, although delayed entitlement to pension benefits reinforced health inequalities. However, both within and between the two groups of articles reviewed, contradictory findings were reported for mental and physical health. For example, the group of articles that assessed the effect of a public pension reform reported both a positive and negative effect on the physical health of workers. Likewise, the group of articles that examined the outcomes of working beyond the retirement age reported both a positive and negative outcome for mental health. These differences may be explained by selection bias in the descriptive studies (see Appendix 3). Specifically, workers may leave the workforce prior to 
retirement due to decreased health. Consequently, predominantly healthier workers remain active in the labor force.

In addition, both groups of articles reported non-comparable findings regarding well-being. For example, while an increase of the statutory retirement age had a negative effect on job satisfaction, working beyond the retirement age instead had a positive effect on work stress. Working beyond the retirement age had no effect on life satisfaction or subjective well-being. Similar to above, these differences may also be explained by selection bias in the descriptive studies (see Appendix 3). Wealthy workers who are less satisfied with their job may decide to retire earlier. As a result, predominantly satisfied workers continue in the labor force.

The negative effect on job satisfaction may also be explained by the mechanism of fairness. A Dutch study that examined the effect of perceptions of altruism and fairness on the evaluation of a public pension system reported that the opinions and preferences of persons were based on their current and predicted financial income (Van der Heijden et al. 1997). The Motivation-Hygiene Theory considers income as a hygiene factor, which does not necessarily increase satisfaction or motivation if this need is fulfilled, but its absence can result in severe dissatisfaction (Herzberg 1964). Since workers financially contribute to the public pension system, either via direct payments or taxes, with the expectation to retire at a certain age, an increase of the retirement age may be perceived as unjust and unfair, and it may thus be considered a breach of this agreement. In addition, if entitlement to pension benefits is delayed, workers are obliged to continue their contributions to this program, but instead receive an equal amount of pension benefits upon retirement. Consequently, such perceived unfair treatment may then be reflected as dissatisfaction with continued labor force participation, hence, decreased job satisfaction.

The discrepancy in the results for health and well-being in both groups of articles may be explained by the use of different aspects of health and well-being in the different studies. There are no indications that these differences could be explained by the quality of the studies. Only one included study that investigated the association of working beyond retirement with health-related outcomes had poor quality with respect to reliability and validity, but the reported findings were comparable with the other publications.

Furthermore, both groups of articles reported that labor force participation had increased. Especially the stream of the literature that investigated the effects of the increased retirement age most frequently reported an increase of labor force participation. The effects on expected and preferred retirement ages were only investigated by studies that examined a public pension reform. These studies reported that the expected and preferred retirement ages increased after a public pension reform that increased the statutory retirement age took effect. Only the group of articles that investigated the outcomes of working beyond the retirement age had assessed the discrepancy between the expected and preferred retirement ages, and it reported that this difference had decreased. This implies that the gap between the age at which one prefers and expects to retire became smaller.

Therefore, although both groups of articles produced similar positive results regarding the labor force participation and perception of the retirement age by older workers, inconclusive results were reported regarding the health of these workers. 


\section{Critical Remarks on the Literature}

Although many countries have increased the statutory retirement age to sustain a healthy public pension system (Bernal and Vermeulen 2014; Bozio 2008; Lüthen 2016; Reynolds et al. 2012; Sewdas et al. 2017; Whitehouse et al. 2009), we observed that only a few studies have actually investigated the health-related effects of such public pension reform on older workers. This finding is consistent with Atalay and Barrett (2014), who observed that only a limited number of studies were published on this topic. We found that after 2014, only three empirical studies were published on this topic. Therefore, there does not seem to exist a solid understanding of the causal relationship of such public pension reform and the health-related outcomes for older workers.

In addition, we found that the reported effects on health were not well comparable. Health was often operationalized differently, which impedes a sound comparison of the findings. While some studies reported a positive effect of a pension reform on aspects of health, other studies instead reported negative effects. A similar pattern was found for the effect on well-being, where only one study investigated the effect of an increased statutory retirement age on job satisfaction. Therefore, the different direction of the reported effects for health and well-being may be explained by inconsistent operationalizations of various aspects of health and well-being in the studies, and as a result of a possible selection bias (see Appendix 3). Workers with decreased health and dissatisfied workers may prematurely leave the labor market before their retirement. Therefore, the reported positive effects may be explained by the fact that predominantly healthy and satisfied workers continue labor force participation beyond the retirement age.

Furthermore, the scarcity of the included studies, and the ambiguity about the existence of a causal relationship as well as the direction of that potential relationship, suggests that this field of research is not yet well investigated. As we excluded studies not written in English, we did not search for policy reports or non-public materials. Therefore, although policymakers have provided many arguments in favor of their decision to increase the statutory retirement age, we found only scarce empirical evidence that can justify those arguments. This is essential, because, while workers in many countries are now obliged to prolong their labor force participation and this research topic thus becomes very relevant (Stenholm and Vahtera 2017), it remains unknown whether the public pension reform could inadvertently have a negative impact on the ability (i.e. based on their health and well-being) of older workers to prolong their labor force participation. Such negative effect on health and well-being would defeat the purpose of the public pension reform and since these workers may then become entitled to disability pension, it may instead strengthen the burden of maintaining a financially sustainable social security system. In this hypothetical case, the public pension reform might instead harm workers. Older workers naturally experience other difficulties and restrictions in their functioning (OECD 2006). The scarcity of these studies that investigated the effects of increasing the statutory retirement age on outcomes for health and well-being is particularly important because facilitating and engaging older workers to work healthily and productively to an older age is becoming more important (De Wind et al. 2016; 
Templer et al. 2010). An effective policy ought to be based on sound empirical evidence.

Similar to public pension reforms, although many studies have investigated the effects of early retirement (Wahrendorf et al. 2017), we found only three empirical studies that investigated the health of older workers in relation to working beyond the retirement age, and only three studies had investigated well-being. The conflicting findings may be explained by considering that the included studies operationalized health and well-being differently, and they measured different aspects of these concepts. In particular, the studies that investigated public pension reforms operationalized health as health inequalities, health promoting behaviors, mental health, physical health, satisfaction with health, and the utilization of healthcare. Well-being was operationalized as job satisfaction. On the contrary, studies that investigated working beyond the retirement age, operationalized health as mental health and physical health. Likewise, well-being was operationalized as life satisfaction, subjective wellbeing, and work stress. Furthermore, the operationalizations were not only inconsistent between but also within the two groups of studies. This variation in approaches makes it difficult to reliably compare the reported findings. This implies that it remains unknown how working beyond the retirement age can influence the health and well-being of older workers, and thus whether labor force participation until higher ages may benefit or harm the workers' health and well-being.

However, we found rather conclusive evidence that public pension reforms indeed increased labor force participation of older workers. People more often remained active on the labor market after a public pension reform that increased the statutory retirement age. This finding is consistent with other studies that also reported that the public pension reforms increased the employment of older workers (Engels et al. 2017; Staubli and Zweimüller 2013). In addition, the preferred and expected retirement age of older workers increased in the direction of the public pension reform. This suggests that, although there was and still remains a fierce opposition against the increase of the statutory retirement age (e.g., Boschman and Van Alphen 2018; Henkens et al. 2016; MAX Vandaag, 2016; PlusOnline 2016), older workers shifted the perception of their retirement age to an older age. This finding is consistent with other research that reported that the public pension reforms increased the preferred retirement age of workers (Hess 2017). Furthermore, consistent with Komp (2018), we also found that the difference between the expected and preferred retirement ages of older workers had decreased. Therefore, considering that the public pension reforms were primarily intended to prolong labor force participation among older workers, we found that these reforms indeed increased the actual and preferred age of retirement among older workers.

\section{Strengths and Limitations}

This study has notable strengths and limitations. A strength involves the broad and multi-disciplinary systematic literature search that was performed using four databases. The search query was optimized for each individual database. In addition, we 
performed snowballing using the reference lists of the included studies to retrieve additional relevant articles.

An important limitation is that few empirical studies were found that could be included in this systematic literature review. Only 12 studies investigated the effect of a public pension reform that increased the statutory retirement age on older workers. Likewise, only seven studies investigated the outcome of working beyond the retirement age on older workers. Although the optimized search queries were constructed in collaboration with two database search experts from the Maastricht University Library, an evaluation of this literature search indicated that indeed only few peer-reviewed empirical studies were published that investigated the effects of an increase of the retirement age on the health and well-being of workers.

Another limitation is that the study selection was performed by one author (PP), which could contribute to selection bias. However, the selection process, screening phases, and results were discussed by all authors until consensus was achieved.

Third, another limitation is that publication bias cannot be excluded. Only published research articles were included, while there might be other unpublished relevant evidence.

Fourth, although empirical studies were not selected based on whether the sample contained public or private sector workers, we observe that many studies included at least or only public sector workers. It is a feature of research conducted in this topic that studies using data for public sector workers are overrepresented. Worldwide, countries have vastly different pension systems, and public sector workers often tend to enjoy more generous pension arrangements than private sector workers or the self-employed (OECD 2019). Because state pension policies may discriminate between public and private sector workers, we suggest that the reported findings should be interpreted in close relationship with the pension policy.

\section{Conclusion}

We conclude that an increase of the retirement age indeed increased labor force participation among older workers, and that it increased their preferred and expected retirement age in the direction of the public pension reform. However, empirical evidence on the effects of an increase of the retirement age on the health and wellbeing of older workers remains scarce and inconclusive.

A major limitation is that studies often operationalize health and well-being differently. Each study investigated one or more aspects of health and well-being, instead of the entire concept. Indeed, this raises the question how these entire concepts should be measured. Consequently, some aspects of health and well-being may be affected differently by an increase of the retirement age, which may explain these different effects.

Furthermore, although older workers (age 45 and older) were included in the studies, the samples were still very heterogenous regarding age, gender, educational level, geography, and occupation of workers. The effects on health and well-being may be different for different groups of workers, where workers who perform physically strenuous work often experience a greater decrease in physical health compared to office workers. Likewise, social security policy 
may protect workers in one jurisdiction, while such protection is less available in other countries. In addition, the effects on health and well-being may be different when measured using self-rating or more objective measures. Also, the effects may be different for older workers who are further away from retirement, compared to older workers who are closer to retirement. The included studies did however not provide sufficient evidence on the effects of these factors.

Our systematic literature review has identified a crucial knowledge gap in the literature. We therefore recommend that future research addresses this gap and investigates the effect of an increase of the retirement age on the health and well-being of older workers. Health and well-being are crucial factors that enable prolonged labor force participation, especially among older workers. More evidence is needed on whether public pension reforms that increased the statutory retirement have a negative or positive impact on health and well-being. If a negative effect exists, the reform may endanger the purpose of increasing the statutory retirement age. Similarly, we recommend more, longitudinal, and preferably experimental research on the effects of labor force participation beyond the retirement age on health and well-being. In addition, we suggest that the influence of age, gender, educational level, geography, occupation, and the difference between subjective and objective measurements of health and well-being of workers on these relationships is studied more frequently.

A sound scientific base of evidence regarding the causality of such public pension reforms on the outcomes for health and well-being of older workers needs to be established. Until then, it remains unclear whether an increase of the retirement age has detrimental effects on the health and well-being of older workers.

\section{Acknowledgements None provided.}

Author's Contributions PP conducted this study. All authors contributed to the text of the manuscript and read and have approved the final article.

Placeholder TextPlaceholder Text

Funding This study was funded by the Maastricht Graduate School of Governance (MGSoG) at Maastricht University.

\section{Compliance with Ethical Standards}

Competing Interests The authors declare that they have no competing interests.

Availability of Data and Material The data and materials are available from the corresponding author.

Code Availability Not applicable. 


\section{Appendix}

Table 6 Search strategy for PubMed

PubMed

Block 1: Employees

Workforce[MeSH] OR work*[tiab] OR employee*[tiab] OR personnel[tiab] OR human resource*[tiab] OR womanpower*[tiab] OR staff*[tiab] OR manpower*[tiab]

Block 2: Public pension reform or Increased retirement age

(Pensions[MeSH] OR pension*[tiab] OR Retirement[MeSH] OR retirement*[tiab] OR retiree*[tiab] OR ((work participation[tiab] OR working life[tiab] OR working lives[tiab] OR employment[tiab]) AND (prolong*[tiab] OR exten*[tiab]))) AND (((increas*[tiab] OR rais*[tiab]) AND (age[tiab] OR ages[tiab])) OR reform*[tiab] OR transform*[tiab] OR change*[tiab] OR abolish*[tiab])

\section{Block 3: Causality or associations}

influenc*[tiab] OR factor[tiab] OR factors[tiab] OR relat*[tiab] OR determinant*[tiab] OR affect*[tiab] OR effect*[tiab] OR predict*[tiab] OR promot*[tiab] OR consequence*[tiab] OR opportun*[tiab] OR expect*[tiab] OR prefer*[tiab] OR impact[tiab]

\section{Block 4: Employee outcomes on micro-level}

Health[MeSH] OR health[tiab] OR employab*[tiab] OR Job Satisfaction[MeSH] OR Personal Satisfaction[MeSH] OR satisfaction[tiab] OR Happiness[MeSH] OR happiness[tiab] OR Occupational stress[MeSH] OR ((job[tiab] OR work[tiab] OR occupation*[tiab]) AND (stress[tiab] OR *security[tiab])) OR wellbeing[tiab] OR Health status[MeSH] OR (health[tiab] AND status[tiab]) OR Quality of Life[MeSH] OR (quality[tiab] AND of[tiab] AND life[tiab]) OR earning*[tiab] OR income[tiab] OR social network*[tiab] OR Health Behavior[MeSH] OR health behavior*[tiab] OR Work Engagement[MeSH] OR engagement[tiab]

\section{Filters:}

Article types: Journal Article, Review, Systematic Reviews

Publication dates: From 01 to $01-2000$

Languages: English

Search strategy for EconLit.

\section{EconLit}

\section{Block 1: Employees}

(ZW “workforce”) OR work* OR employee* OR (ZW “personnel”) OR personnel OR human resource* OR womanpower* OR staff* OR manpower*

\section{Block 2: Public pension reform or Increased retirement age}

((ZW “pension”) OR (ZW “pensions") OR pension* OR (ZW “retirement”) OR retirement* OR retiree* OR ((work participation OR working life OR working lives OR employment) AND (prolong* OR exten*))) AND (((increas* OR rais*) AND (age OR ages)) OR reform* OR transform* OR change* OR abolish*)

\section{Block 3: Causality or associations}

influenc* OR factor OR factors OR relat* OR determinant* OR affect* OR effect* OR predict* OR promot* OR consequence* OR opportun* OR expect* OR prefer* OR impact

\section{Block 4: Employee outcomes on micro-level}

(ZW "health") OR health OR employab* OR (ZW "job satisfaction”) OR satisfaction OR (ZW "happiness") OR happiness OR (ZW “occupational stress") OR ((job OR work OR occupation*) AND (stress OR *security)) OR (ZW “wellbeing”) OR wellbeing OR (ZW "health status") OR (health AND status) OR (ZW "quality of life") OR (quality AND of AND life) OR earning* OR income OR social network* OR (ZW "health behavior") OR (ZW "health behaviors") OR health behavior* OR (ZW “engagement") OR engagement

\section{Filters:}

Source Types: Academic Journals 
Table 6 (continued)

Limit To: From year 2000

Language: English

Search strategy for SocINDEX.

SocINDEX

Block 1: Employees

(DE “LABOR supply") OR work* OR (DE “EMPLOYEES”) OR employee* OR personnel OR human resource* OR womanpower* OR staff* OR manpower*

\section{Block 2: Public pension reform or Increased retirement age}

((DE “PENSIONS”) OR pension* OR (DE "RETIREMENT") OR retirement* OR retiree* OR ((work participation OR working life OR working lives OR employment) AND (prolong* OR exten*))) AND (((increas* OR rais*) AND (age OR ages)) OR reform* OR transform* OR change* OR abolish*)

Block 3: Causality or associations

influenc* OR factor OR factors OR relat* OR determinant* OR affect* OR effect* OR predict* OR promot* OR consequence* OR opportun* OR expect* OR prefer* OR impact

Block 4: Employee outcomes on micro-level

DE "HEALTH” OR health OR employab* OR DE "JOB satisfaction” OR DE "SATISFACTION" OR satisfaction OR DE "HAPPINESS” OR happiness OR DE “JOB stress” OR ((job OR work OR occupation*) AND (stress OR *security)) OR wellbeing OR (health AND status) OR DE "QUALITY of life" OR (quality AND of AND life) OR earning* OR income OR social network* OR DE "HEALTH behavior" OR health behavior* OR engagement

\section{Filters:}

Source Types: Academic Journals, Reviews

Publication Date: From year 2000

Language: English

Limit To: Scholarly (Peer Reviewed) Journals

Search strategy for PsycINFO.

\section{PsycINFO}

\section{Block 1: Employees}

work* OR employee* OR personnel OR human resource* OR womanpower* OR staff* OR manpower*

Block 2: Public pension reform or Increased retirement age

(DE "Employee Pension Plans" OR pension* OR DE "Retirement" OR retirement* OR retiree* OR ((work participation OR working life OR working lives OR employment) AND (prolong* OR exten*))) AND (((increas* OR rais*) AND (age OR ages)) OR reform* OR transform* OR change* OR abolish*)

Block 3: Causality or associations

influenc* OR factor OR factors OR relat* OR determinant* OR affect* OR effect* OR predict* OR promot* OR consequence* OR opportun* OR expect* OR prefer* OR impact

Block 4: Employee outcomes on micro-level

DE "Health" OR health OR employab* OR DE "Job Satisfaction" OR DE "Satisfaction" OR satisfaction OR DE "Happiness” OR happiness OR DE “Occupational Stress” OR ((job OR work OR occupation*) AND (stress OR *security)) OR wellbeing OR DE "Health Status" OR (health AND status) OR DE "Quality of Life" OR (quality AND of AND life) OR earning* OR income OR social network* OR DE "Health Behavior" OR health behavior* OR DE "Employee Engagement" OR engagement

Filters:

Source Types: Academic Journals

Publication Date: From 01 to 01-2000

Languages: English 
Table 7 PRISMA Checklist

\begin{tabular}{lll}
\hline Section/topic $\quad$ Checklist item & $\begin{array}{l}\text { Reported on } \\
\text { page \# }\end{array}$ & \begin{tabular}{l} 
Page \\
\hline
\end{tabular} \\
\hline
\end{tabular}

TITLE

Title

\section{ABSTRACT}

Structured summary

\section{INTRODUCTION}

Rationale

Objectives

\section{METHODS}

Protocol and registration

Eligibility criteria

Information sources

Search

Study selection

Data collection process

Data items

Risk of bias in individual studies

Summary measures

Synthesis of results

Section/topic

\section{\# Checklist item} means).
1 Identify the report as a systematic review, meta-analysis, or both. 1

2 Provide a structured summary including, as applicable: background; 4 objectives; data sources; study eligibility criteria, participants, and interventions; study appraisal and synthesis methods; results; limitations; conclusions and implications of key findings; systematic review registration number.

3 Describe the rationale for the review in the context of what is 7 already known.

4 Provide an explicit statement of questions being addressed with 8 reference to participants, interventions, comparisons, outcomes, and study design (PICOS).

5 Indicate if a review protocol exists, if and where it can be accessed N/A (e.g., Web address), and, if available, provide registration information including registration number.

6 Specify study characteristics (e.g., PICOS, length of follow-up) and 9 report characteristics (e.g., years considered, language, publication status) used as criteria for eligibility, giving rationale.

7 Describe all information sources (e.g., databases with dates of coverage, contact with study authors to identify additional studies) in the search and date last searched.

8 Present full electronic search strategy for at least one database, including any limits used, such that it could be repeated.

9 State the process for selecting studies (i.e., screening, eligibility, included in systematic review, and, if applicable, included in the meta-analysis).

10 Describe method of data extraction from reports (e.g., piloted forms, 10 independently, in duplicate) and any processes for obtaining and confirming data from investigators.

11 List and define all variables for which data were sought (e.g., PICOS, funding sources) and any assumptions and simplifications made.

12 Describe methods used for assessing risk of bias of individual studies (including specification of whether this was done at the study or outcome level), and how this information is to be used in any data synthesis.

13 State the principal summary measures (e.g., risk ratio, difference in N/A

14 Describe the methods of handling data and combining results of studies, if done, including measures of consistency (e.g., I2) for each meta-analysis. 
Table 7 (continued)

$\begin{array}{lll}\text { Section/topic } \quad \# \quad \text { Checklist item } & \begin{array}{l}\text { Reported on } \\ \text { page \# }\end{array}\end{array}$

\section{Risk of bias across studies}

Additional analyses

\section{RESULTS}

Study selection

Study characteristics

Risk of bias within studies

Results of individual studies

Synthesis of results

Risk of bias across studies

Additional analysis

\section{DISCUSSION}

Summary of evidence

Limitations

Conclusions

\section{FUNDING}

Funding
Specify any assessment of risk of bias that may affect the cumulative evidence (e.g., publication bias, selective reporting within studies).

16 Describe methods of additional analyses (e.g., sensitivity or subgroup analyses, meta-regression), if done, indicating which were pre-specified.

17 Give numbers of studies screened, assessed for eligibility, and included in the review, with reasons for exclusions at each stage, ideally with a flow diagram.

18 For each study, present characteristics for which data were extracted (e.g., study size, PICOS, follow-up period) and provide the citations.

19 Present data on risk of bias of each study and, if available, any outcome level assessment (see item 12).

20 For all outcomes considered (benefits or harms), present, for each study: (a) simple summary data for each intervention group (b) effect estimates and confidence intervals, ideally with a forest plot.

21 Present results of each meta-analysis done, including confidence intervals and measures of consistency.

22 Present results of any assessment of risk of bias across studies (see N/A Item 15).

23 Give results of additional analyses, if done (e.g., sensitivity or N/A subgroup analyses, meta-regression [see Item 16]).

24 Summarize the main findings including the strength of evidence for each main outcome; consider their relevance to key groups (e.g., healthcare providers, users, and policy makers).

25 Discuss limitations at study and outcome level (e.g., risk of bias), 24 and at review-level (e.g., incomplete retrieval of identified research, reporting bias).

26 Provide a general interpretation of the results in the context of other 24 evidence, and implications for future research.

27 Describe sources of funding for the systematic review and other 3 support (e.g., supply of data); role of funders for the systematic review.

From: Moher D., Liberati A., Tetzlaff J., Altman D. G., The PRISMA Group. (2009). Preferred Reporting Items for Systematic Reviews and Meta-Analyses: The PRISMA Statement. PLoS Medicine 6(7): e1000097. doi:https://doi.org/10.1371/journal.pmed1000097

For more information, visit: www.prisma-statement.org. 


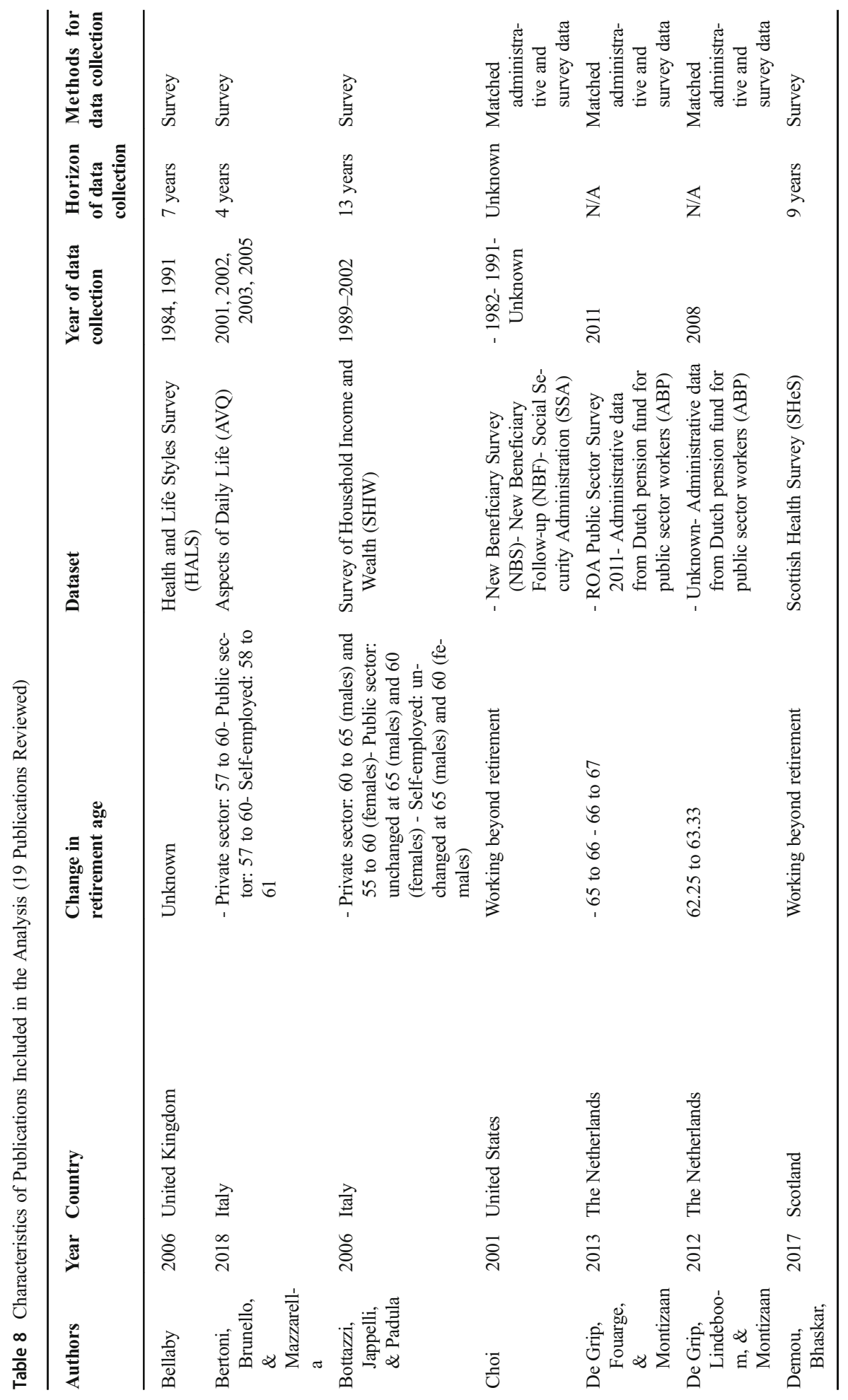




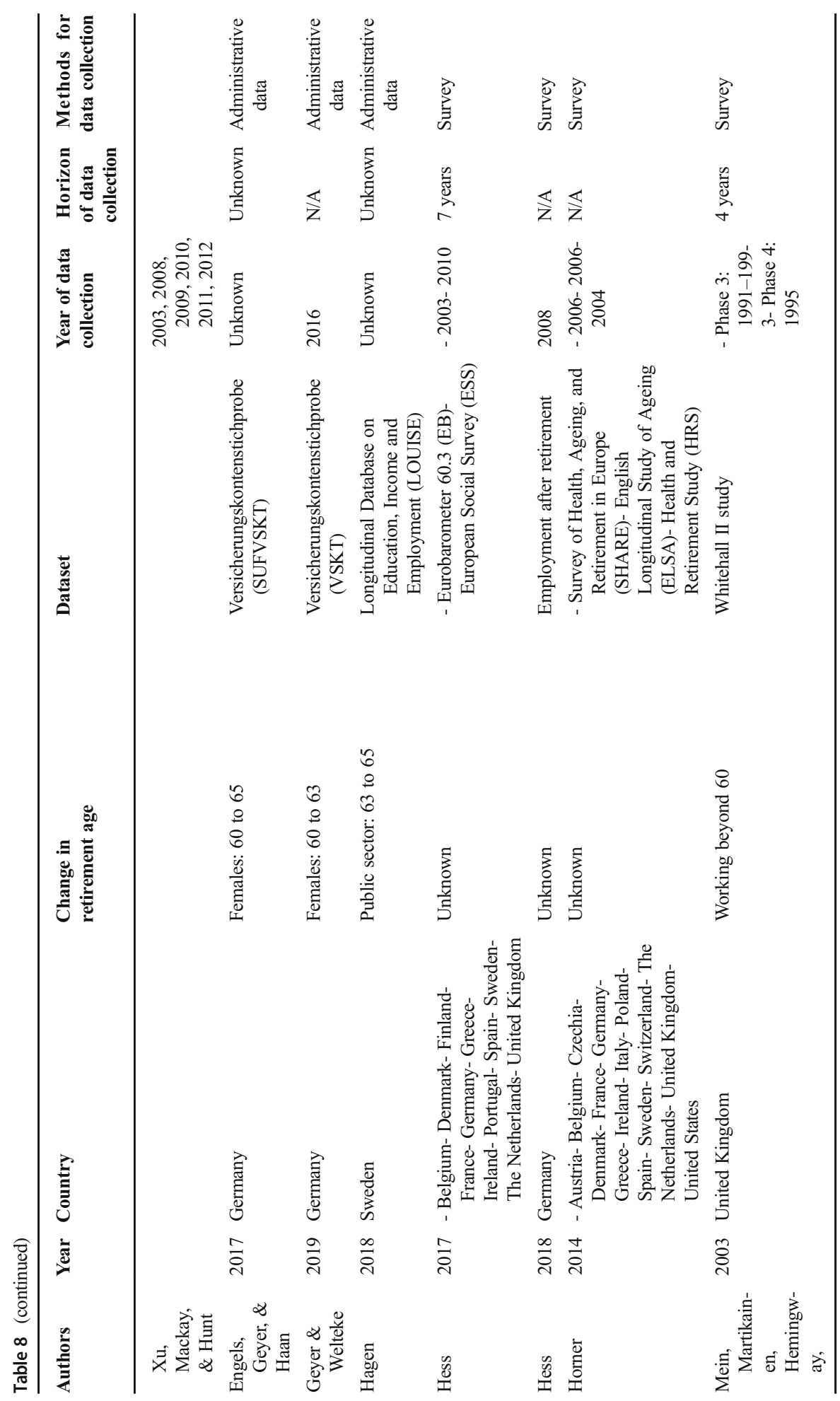




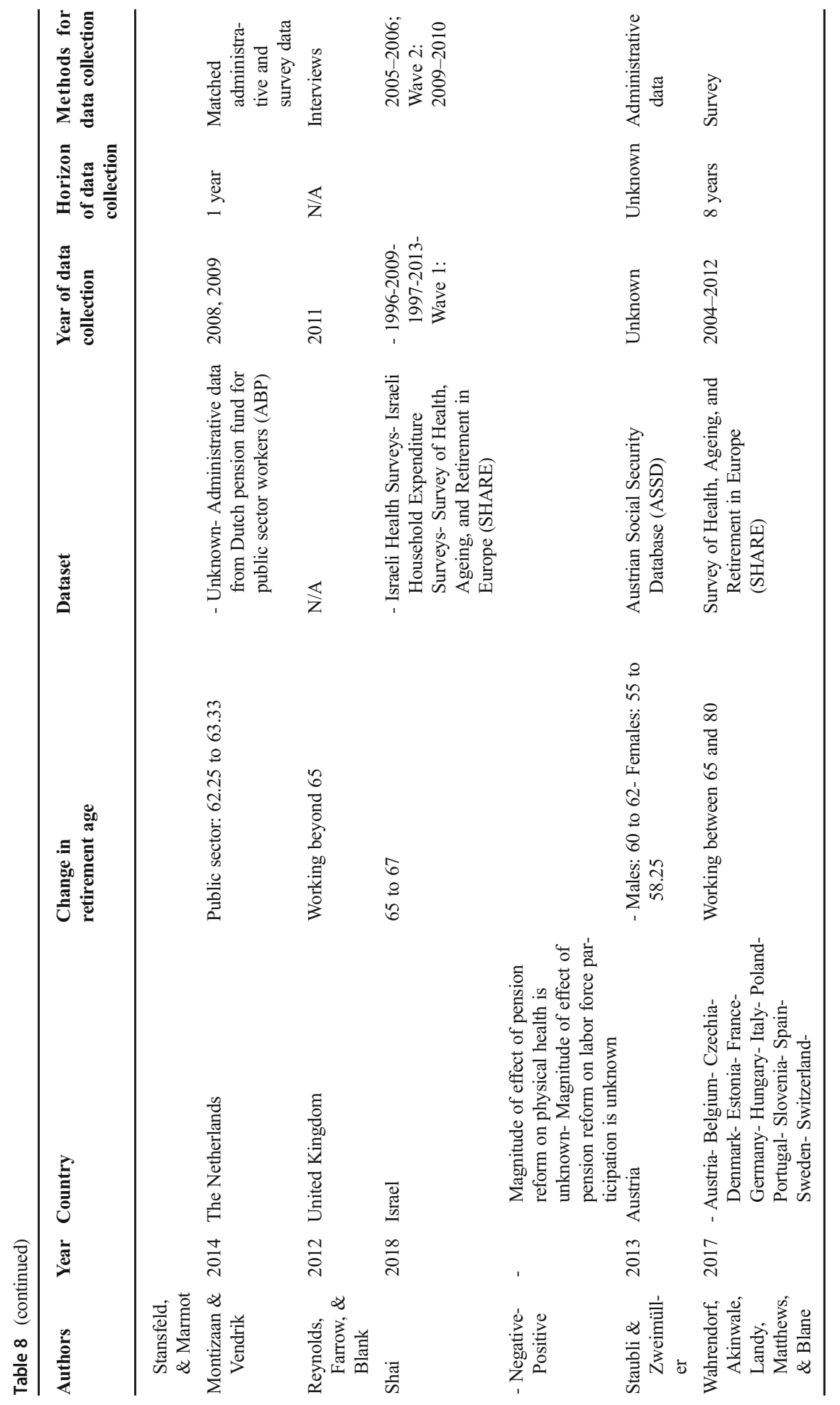




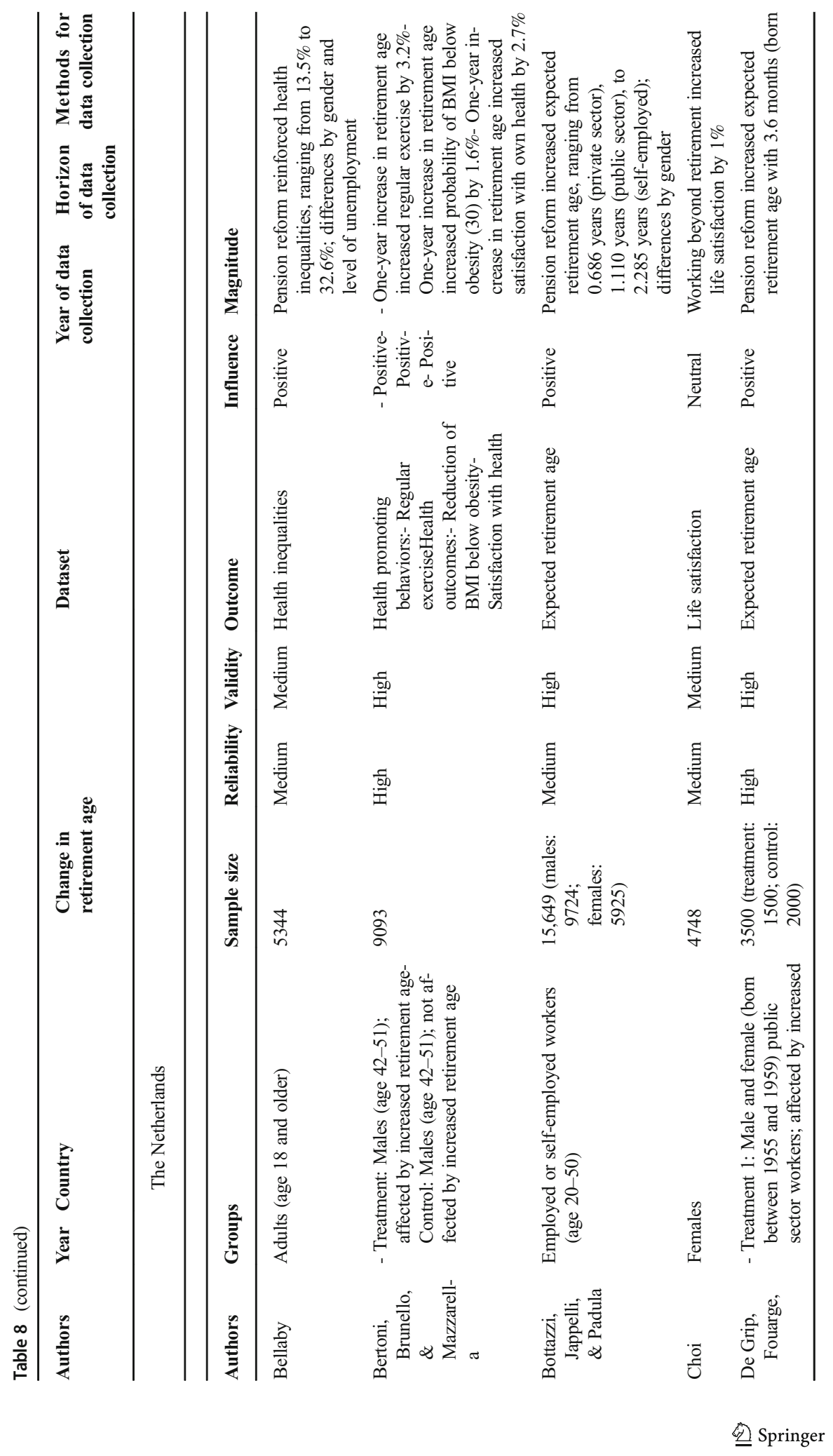




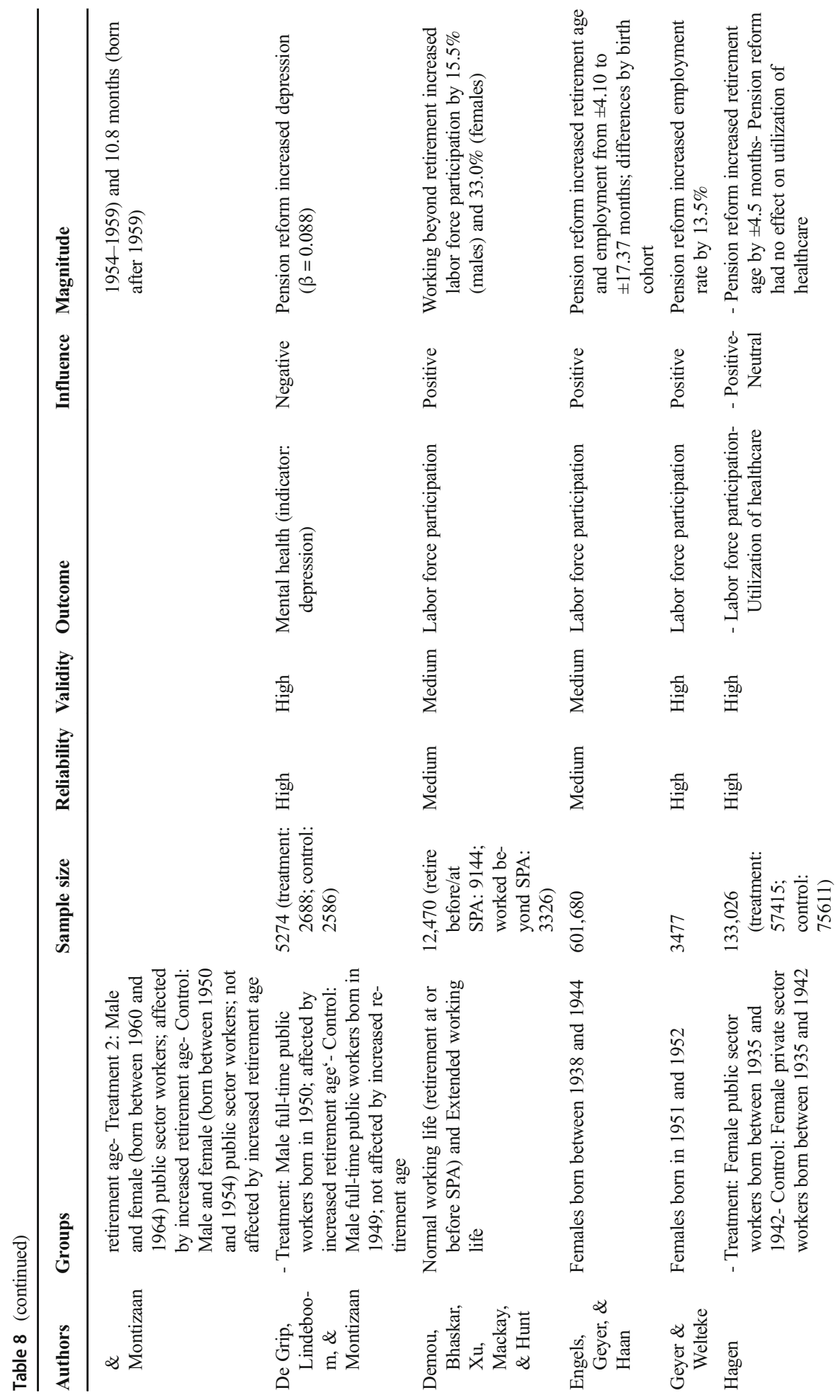




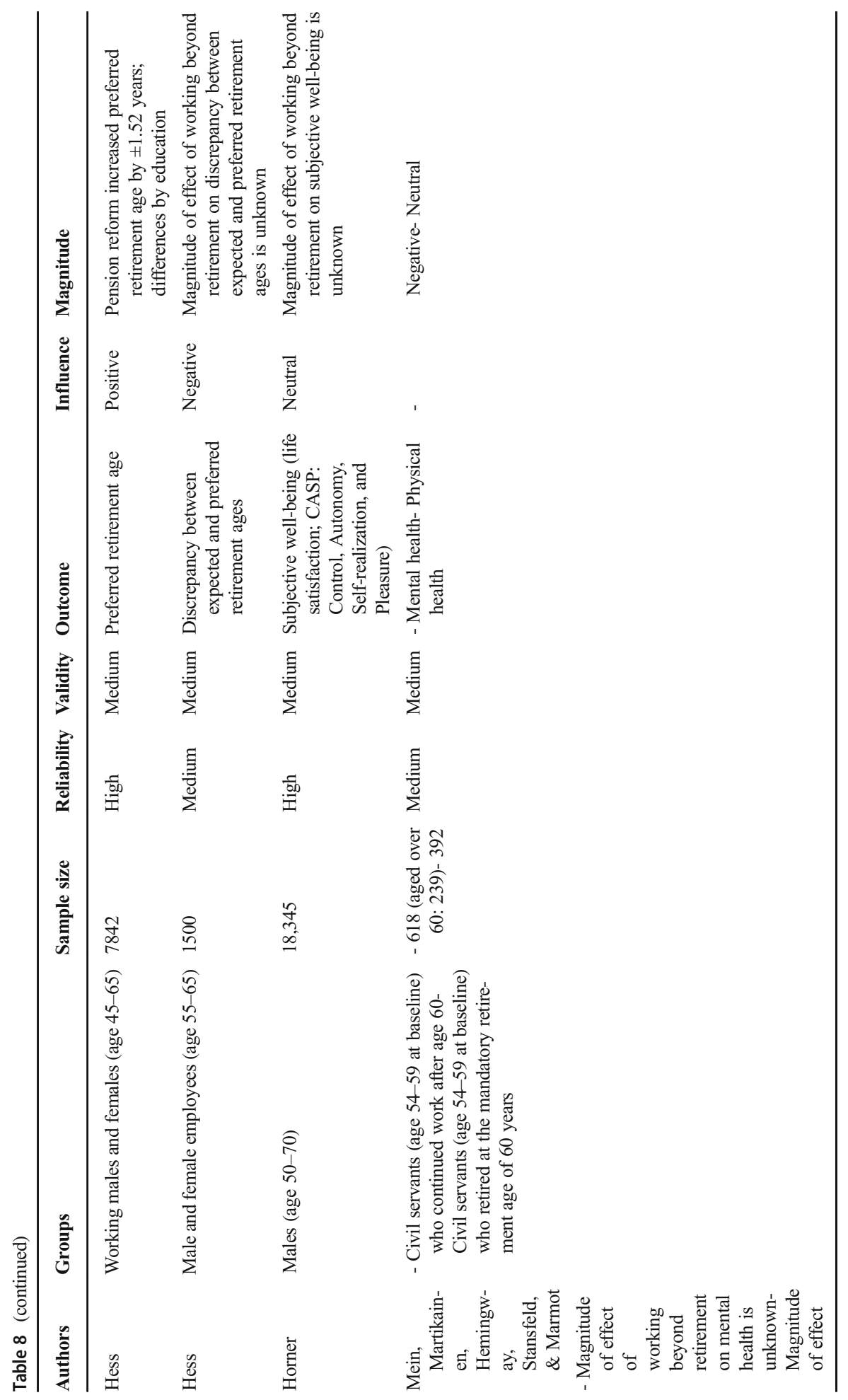




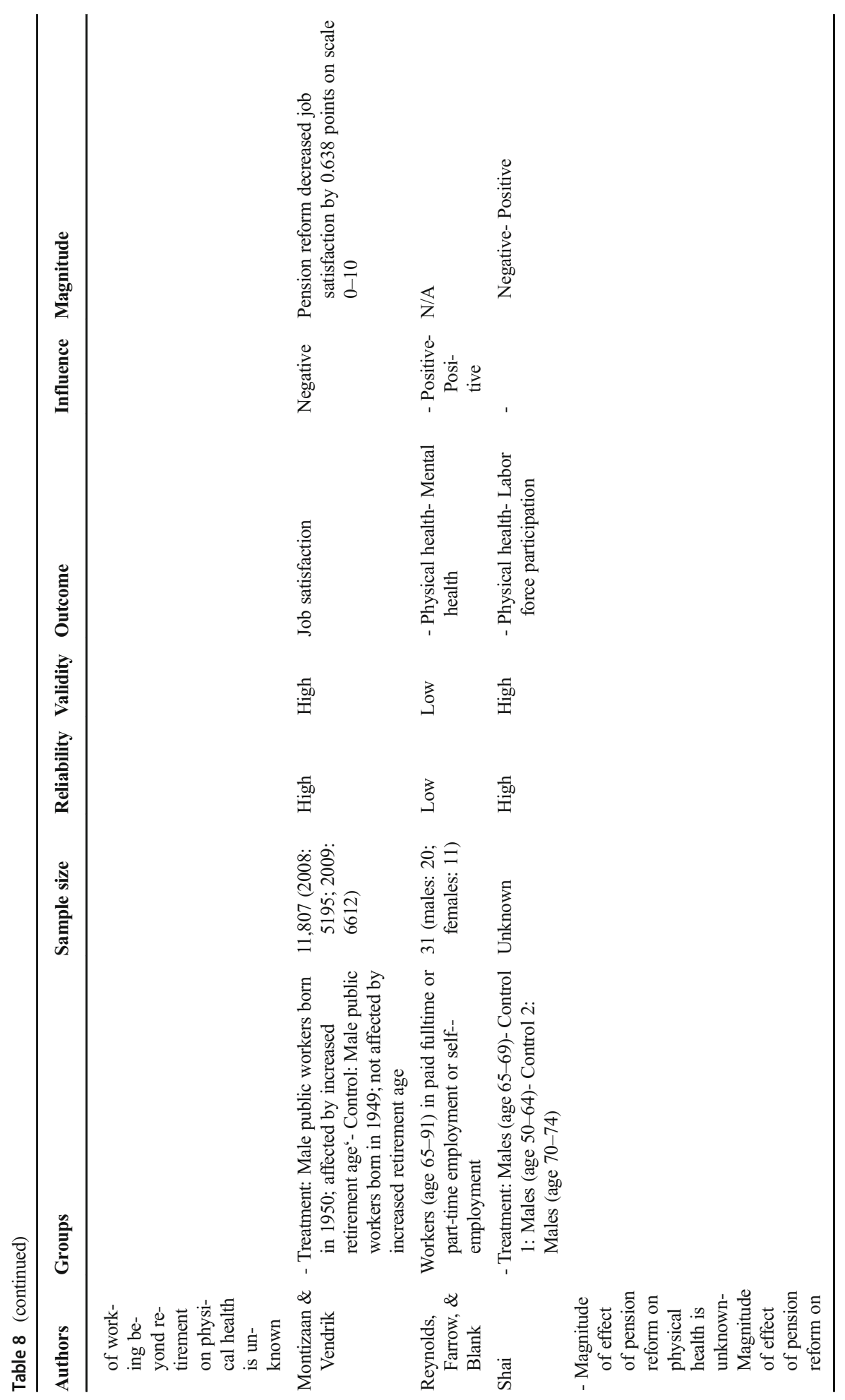




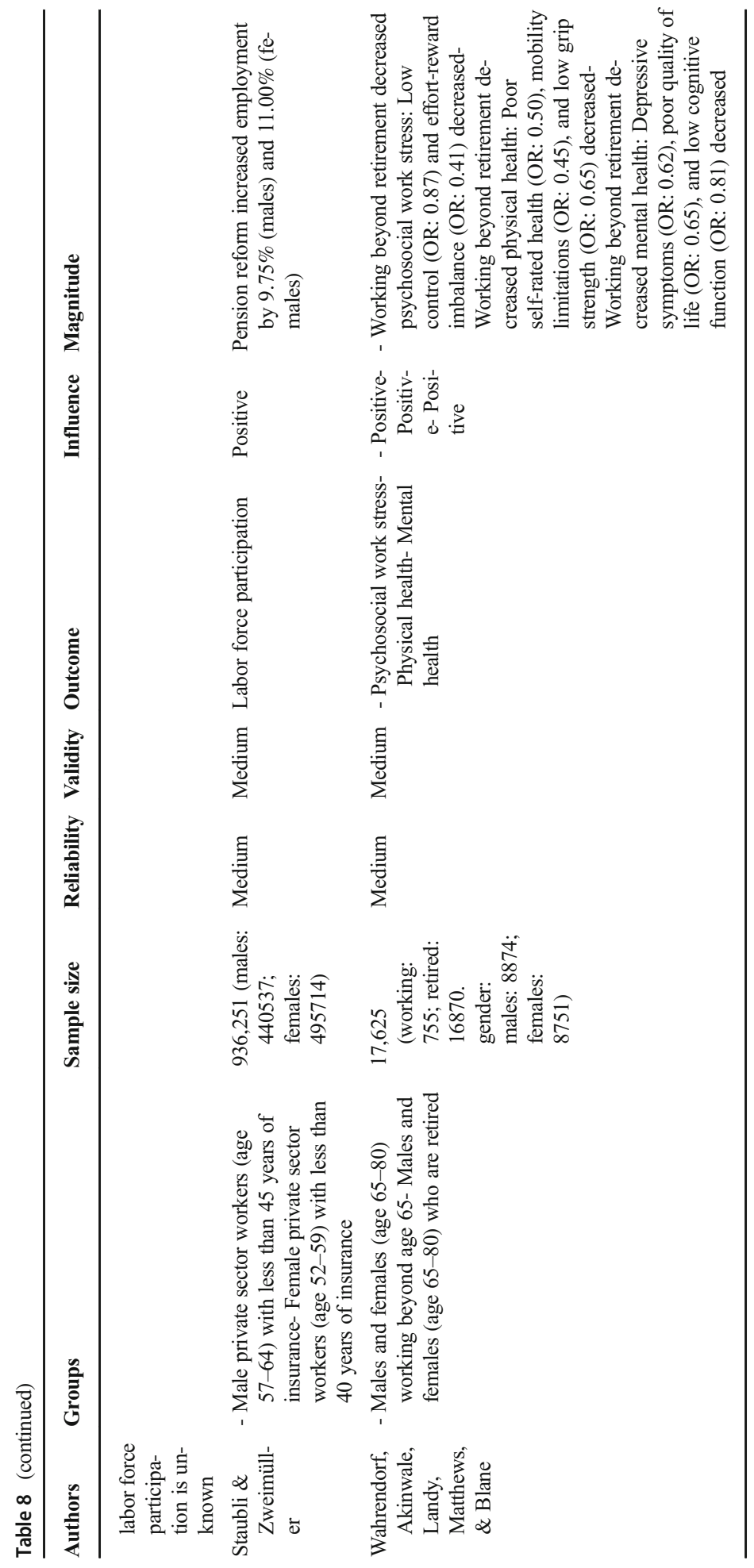


Open Access This article is licensed under a Creative Commons Attribution 4.0 International License, which permits use, sharing, adaptation, distribution and reproduction in any medium or format, as long as you give appropriate credit to the original author(s) and the source, provide a link to the Creative Commons licence, and indicate if changes were made. The images or other third party material in this article are included in the article's Creative Commons licence, unless indicated otherwise in a credit line to the material. If material is not included in the article's Creative Commons licence and your intended use is not permitted by statutory regulation or exceeds the permitted use, you will need to obtain permission directly from the copyright holder. To view a copy of this licence, visit http://creativecommons.org/licenses/by/4.0/.

\section{References}

Atalay, K., \& Barrett, G. F. (2014). The causal effect of retirement on health: New evidence from Australian pension reform. Economics Letters, 125(3), 392-395.

Banks, J., \& Smith, S. (2006). Retirement in the UK. Oxford Review of Economic Policy, 22(1), 40-56.

Barr, N. (2012). Economics of the welfare state (5th ed.). Oxford: Oxford University Press.

BBC News. (2018). Russia pension: Protests over retirement age hikes. Retrieved from https://www.bbc. com/news/world-europe-44675582

Bellaby, P. (2006). Can they carry on working? Later retirement, health, and social inequality in an aging population. International Journal of Health Services, 36(1), 1-23.

Bernal, N., \& Vermeulen, F. (2014). The impact of an increase in the legal retirement age on the effective retirement age. De Economist, 162(2), 115-145.

Bertoni, M., Brunello, G., \& Mazzarella, G. (2018). Does postponing minimum retirement age improve healthy behaviors before retirement? Evidence from middle-aged Italian workers. Journal of Health Economics, 58, 215-227.

Boschman, O., \& Van Alphen, F. (2018). Dutch parliament: Government must slow down retirement age increases. Retrieved from https://www.ipe.com/countries/netherlands/dutch-parliament-governmentmust-slow-down-retirement-age-increases/10028306.article

Bottazzi, R., Jappelli, T., \& Padula, M. (2006). Retirement expectations, pension reforms, and their impact on private wealth accumulation. Journal of Public Economics, 90(12), 2187-2212.

Bozio, A. (2008). Impact evaluation of the 1993 French pension reform on retirement age. Pensions: An International Journal, 13(4), 207-212.

Bramer, W. M., Giustini, D., de Jonge, G. B., Holland, L., \& Bekhuis, T. (2016). De-duplication of database search results for systematic reviews in EndNote. Journal of the Medical Library Association: JMLA, 104(3), 240-243.

Buyse, T., Heylen, F., \& Van de Kerckhove, R. (2013). Pension reform, employment by age, and long-run growth. Journal of Population Economics, 26(2), 769-809.

CBS News. (2010). Violent Protests in France over Retirement Age. Retrieved from https://www.cbsnews. com/news/violent-protests-in-france-over-retirement-age/

Choi, N., \& G. (2001). Relationship between life satisfaction and postretirement employment among older women. The International Journal of Aging and Human Development, 52(1), 45-70.

De Grip, A., Fouarge, D., \& Montizaan, R. (2013). How sensitive are individual retirement expectations to raising the retirement age? De Economist, 161(3), 225-251.

De Grip, A., Lindeboom, M., \& Montizaan, R. (2012). Shattered dreams: The effects of changing the pension system late in the game. Economic Journal, 122(559), 1-25.

De Meijer, C., Wouterse, B., Polder, J., \& Koopmanschap, M. (2013). The effect of population aging on health expenditure growth: A critical review. European Journal of Ageing, 10(4), 353-361.

De Wind, A., Van der Pas, S., Blatter, B. M., \& Van der Beek, A. J. (2016). A life course perspective on working beyond retirement-Results from a longitudinal study in the Netherlands. BMC Public Health, $16(1), 499$.

Demou, E., Bhaskar, A., Xu, T., Mackay, D. F., \& Hunt, K. (2017). Health, lifestyle and employment beyond state-pension age. BMC Public Health, 17(1), 971.

Denton, F. T., \& Spencer, B. G. (2009). What is retirement? A review and assessment of alternative concepts and measures. Canadian Journal on Aging / La Revue canadienne du vieillissement, 28(1), 63-76.

Domonkos, S. (2015). Promoting a higher retirement age: A prospect-theoretical approach. International Journal of Social Welfare, 24(2), 133-144. 
Engels, B., Geyer, J., \& Haan, P. (2017). Pension incentives and early retirement. Labour Economics, 47, $216-231$. European Commission. (2006). De demografische toekomst van Europa: Probleem of uitdaging? [The demographic future of Euroe: Problem or opportunity?]. Brussels: Commission of the European Communities.

European Commission. (2012). Pension adequacy in the European Union 2010-2050. Luxembourg: Publications Office of the European Union.

European Commission. (2013). The 2012 ageing report: Economic and budgetary projections for the 27 EU member states (2010-2060). Brussels: European Union.

Eurostat. (2018). Record high old-age dependency ratio in the EU. Retrieved from https://ec.europa. eu/eurostat/web/products-eurostat-news/-/DDN-20180508-1

Geyer, J., \& Welteke, C. (2019). Closing routes to retirement for women: How do they respond? The Journal of Human Resources, 1-46.

Hagen, J. (2018). The effects of increasing the normal retirement age on health care utilization and mortality. Journal of Population Economics, 31, 193-234.

Harper, S. (2015). The challenges of twenty-first-century demography. In C. Torp (Ed.), Challenges of aging: Retirement, pensions, and intergenerational justice (pp. 17-30). Houndmills, United Kingdom: Palgrave Macmillan.

Heintz, J. (2018). Tens of thousands of Russians protest retirement age hikes. Retrieved from https://apnews. com/07039ed986a54d43940144282f0c431a

Henkens, K., Van Solinge, H., Damman, M., \& Dingemans, E. (2016). Langer doorwerken valt nog niet mee [working longer is not easy]. Demos, 32(2), 1-4.

Hernæs, E., Markussen, S., Piggott, J., \& Røed, K. (2016). Pension reform and labor supply. Journal of Public Economics, 142, 39-55.

Herzberg, F. (1964). The motivation-hygiene concept of problems of manpower. Personnel Administration(27), 3-7.

Hess, M. (2017). Rising preferred retirement age in Europe: Are Europe's future pensioners adapting to pension system reforms? Journal of Aging \& Social Policy, 29(3), 245-261.

Hess, M. (2018). Expected and preferred retirement age in Germany. Zeitschrift für Gerontologie und Geriatrie, 51(1), 98-104.

Hill, A. (2018). At least 1000 women protest at changes to UK pension age. Retrieved from https://www. theguardian.com/lifeandstyle/2018/oct/10/thousand-women-protest-at-changes-to-uk-pension-age

Hofäcker, D., Hess, M., \& Naumann, E. (2015). Changing retirement transitions in times of paradigmatic political change: Towards growing inequalities? In C. Torp (Ed.), Challenges of aging: Retirement, pensions, and intergenerational justice (pp. 205-226). Houndmills, United Kingdom: Palgrave Macmillan.

Horner, E. M. (2014). Subjective well-being and retirement: Analysis and policy recommendations. Journal of Happiness Studies, 15(1), 125-144.

Hsieh, H.-F., \& Shannon, S. E. (2005). Three approaches to qualitative content analysis. Qualitative Health Research, 15(9), 1277-1288.

Kampmeijer, R., Pavlova, M., Tambor, M., Golinowska, S., \& Groot, W. (2016). The use of e-health and mhealth tools in health promotion and primary prevention among older adults: A systematic literature review. BMC Health Services Research, 16(Suppl 5), 290.

Kohli, M., \& Arza, C. (2011). The political economy of pension reform in Europe. In R. H. Binstock \& L. K. George (Eds.), Handbook of aging and the social sciences (pp. 251-264). London: Elsevier.

Komp, K. (2018). Shifts in the realized retirement age: Europe in times of pension reform and economic crisis. Journal of European Social Policy, 28(2), 130-142.

Kosloski, K., Ekerdt, D., \& DeViney, S. (2001). The role of job-related rewards in retirement planning. The Journals of Gerontology: Series B, 56(3), P160-P169.

Liberati, A., Altman, D. G., Tetzlaff, J., Mulrow, C., Gøtzsche, P. C., Ioannidis, J. P. A., \& Moher, D. (2009). The PRISMA statement for reporting systematic reviews and meta-analyses of studies that evaluate healthcare interventions: Explanation and elaboration. BMJ, 339, b2700.

Lüthen, H. (2016). Rates of return and early retirement disincentives: Evidence from a German pension reform. German Economic Review, 17(2), 206-233.

Mein, G., Martikainen, P., Hemingway, H., Stansfeld, S., \& Marmot, M. (2003). Is retirement good or bad for mental and physical health functioning? Whitehall II longitudinal study of civil servants. Journal of Epidemiology \& Community Health, 57(1), 46-49.

Moher, D., Liberati, A., Tetzlaff, J., Altman, D. G., \& The PRISMA Group. (2009). Preferred reporting items for systematic reviews and meta-analyses: The PRISMA statement. PLoS Medicine, 6(7), e1000097. 
Montizaan, R. M., \& Vendrik, M. C. M. (2014). Misery loves company: Exogenous shocks in retirement expectations and social comparison effects on subjective well-being. Journal of Economic Behavior and Organization, 97, 1-26.

Nishimura, Y., Oikawa, M., \& Motegi, H. (2018). What explains the difference in the effect of retirement on health? Evidence from global aging data. Journal of Economic Surveys, 32(3), 792-847.

OECD. (2006). Live longer, work longer. Paris: OECD Publishing.

OECD. (2019). Pensions at a glance 2019: OECD and G20 indicators. Paris, France: OECD Publishing.

PlusOnline. (2016). Ontevredenheid over pensioenakkoord [Dissatisfaction with pension agreement]. Retrieved from https://www.plusonline.nl/pensioen/ontevredenheid-over-pensioenakkoord

Reguly, E. (2012, May 8, 2018). Raising retirement age a risky move for governments. Retrieved from https://www.theglobeandmail.com/news/politics/budget/raising-retirement-age-a-risky-move-forgovernments/article4097246/

Reynolds, F., Farrow, A., \& Blank, A. (2012). "Otherwise it would be nothing but cruises": exploring the subjective benefits of working beyond 65. International Journal of Ageing and Later Life, 7(1), 79-106.

Sewdas, R., De Wind, A., Van der Zwaan, L. G. L., Van der Borg, W. E., Steenbeek, R., Van der Beek, A. J., \& Boot, C. R. L. (2017). Why older workers work beyond the retirement age: A qualitative study. $B M C$ Public Health, 17(1), 672.

Shai, O. (2018). Is retirement good for men's health? Evidence using a change in the retirement age in Israel. Journal of Health Economics, 57, 15-30.

Staubli, S., \& Zweimüller, J. (2013). Does raising the early retirement age increase employment of older workers? Journal of Public Economics, 108, 17-32.

Stenholm, S., \& Vahtera, J. (2017). Does retirement benefit health? Preventive Medicine, 100, 294-295.

Templer, A., Armstrong-Stassen, M., \& Cattaneo, J. (2010). Antecedents of older workers' motives for continuing to work. Career Development International, 15(5), 479-500.

Tolos, H., Wang, P., Zhang, M., \& Shand, R. (2014). Retirement systems and pension reform: A Malaysian perspective. International Labour Review, 153(3), 489-502.

Van der Heijden, E. C. M., Nelissen, J. H. M., \& Verbon, H. A. A. (1997). Altruism and fairness in a public pension system. Journal of Economic Behavior \& Organization, 32(4), 505-518.

MAX Vandaag. (2016). 60-plusser boos over verhoging pensioenleeftijd [People over the age of 60 angry about raising retirement age]. Retrieved from https://www.maxvandaag.nl/sessies/themas/geld-werkrecht/60-plusser-boos-over-verhoging-pensioenleeftijd/

Vogel, E., Ludwig, A., \& Börsch-Supan, A. (2017). Aging and pension reform: Extending the retirement age and human capital formation. Journal of Pension Economics and Finance, 16(1), 81-107.

Wahrendorf, M., Akinwale, B., Landy, R., Matthews, K., \& Blane, D. (2017). Who in Europe works beyond the state pension age and under which conditions? Results from SHARE. Journal of Population Ageing, 10(3), 269-285.

Walker, A. (2008). Commentary: The emergence and application of active aging in Europe. Journal of Aging \& Social Policy, 21(1), 75-93.

Wang, M., \& Shi, J. (2014). Psychological research on retirement. Annual Review of Psychology, 65(1), $209-233$.

Wheaton, F., \& Crimmins, E. M. (2012). The demography of aging and retirement. In M. Wang (Ed.), The Oxford handbook of retirement (pp. 22-41). New York: Oxford University Press.

Whitehouse, E., D'Addio, A., Chomik, R., \& Reilly, A. (2009). Two decades of pension reform: What has been achieved and what remains to be done? The Geneva Papers on Risk and Insurance - Issues and Practice, 34(4), 515-535.

Publisher's Note Springer Nature remains neutral with regard to jurisdictional claims in published maps and institutional affiliations. 


\section{Affiliations}

\section{Patrick Pilipiec $^{1} \cdot$ Wim Groot ${ }^{2} \cdot$ Milena Pavlova $^{3}$}

Wim Groot

w.groot@maastrichtuniversity.nl

Milena Pavlova

m.pavlova@maastrichtuniversity.nl

1 School of Business and Economics, Maastricht University, Tongersestraat 53, 6211 LMMaastricht, The Netherlands

2 School of Business and Economics; Department of Health Services Research; CAPHRI; Maastricht University Medical Center; Faculty of Health, Medicine and Life Sciences, Maastricht University, Boschstraat 24, 6211 AXMaastricht, The Netherlands

3 Department of Health Services and Research; CAPHRI; Maastricht University Medical Center; Faculty of Health, Medicine and Life Sciences, Maastricht University, Duboisdomein 30, 6229 GTMaastricht, The Netherlands 